\title{
PROCESOS DEMOGRÁFICOS Y URBANOS EN LA TRANSFORMACIÓN ESPACIAL DE LA CIUDAD DE ÁVILA
}

\author{
Luis Carlos Martínez Fernández, Ignacio Molina de la Torre y José María Delgado Urrecho \\ Departamento de Geografía \\ Universidad de Valladolid
}

\section{RESUMEN}

La ciudad de Ávila se configura, en la actualidad, como un compacto entramado urbano. Este ha conocido un crecimiento espacial sin precedentes a lo largo de los últimos sesenta años y, particularmente, durante la primera década de los años dos mil, fruto de una vinculación, que no siempre está correspondida, entre la evolución poblacional y el desarrollo residencial. Una ampliación del espacio construido -cuyo soporte estratégico se ha fundamentado, además, en la dialéctica establecida entre el centro y la periferia- dimensionado desorbitadamente por la conjunción de una serie de intereses urbanísticos completamente truncados por el estallido de la crisis. Esta manera de seguir construyendo la ciudad -recogida explícitamente por el planeamiento- parece ser más una utopía que una realidad, a tenor de las proyecciones de población realizadas que atisban un horizonte demográfico a corto y medio plazo nada halagüeño.

Palabras clave: Transformación espacial, dinámica demográfica, estructura urbana, Ávila, proyección de población.

\section{ABSTRACT}

\section{Demographic and urban processes in the spatial transformation of the city of Ávila}

The city of Avila is configured, currently, as a compact urban structure. This space has seen a unprecedented growth over the last sixty years and, particularly, during the first decade of the new century, which is not always reciprocated between the population evolution and residential development. An extension of the urban space -whose strategic support has also established based on the dialectic between center and periphery- sized exorbitantly by the conjunction of a number of urban interests completely truncated by the economic crisis. This way to continue building the city -which are stated explicitly by urban planning- seems to be more a utopia than a reality, according to population projections that herald a demographic horizon not flattering.

Key words: Spatial transformation, demographic dynamics, urban structure, Ávila, population projection.

\section{LA ESTRUCTURA URBANA DE ÁVILA Y SU EVOLUCIÓN AL COMPÁS DE LAS DINÁMICAS DEMOGRÁFICAS DE LOS ÚLTIMOS SESENTA AÑOS}

La organización del entramado urbano de Ávila (Figura 1) se define a partir de un "centro" paulatinamente alargado y desplazado hacia el Este ${ }^{1}$, que puede ser identificado con la ciudad histórica (Villar, 1982 y 1984). Dentro ella se diferenciaban claramente una serie de espacios más o menos contiguos: el Centro-Intramuros, verdadero elemento original dentro del recinto amurallado, con su casalicio apiñado sobre las abigarradas calles, y una orla completa de arrabales -Cuatro Postes, San Nicolás, Las Vacas, Extramuros- como evidencias de las primeras expansiones, de misma raíz medieval, del tejido construido.

Contacto: Luis Carlos Martínez Fernández: luiscar@fyl.uva.es; Ignacio Molina de la Torre: imolina@fyl.uva.es; José María Delgado Urrecho: jose@fyl.uva.es

1 Que se prolonga desde la plaza del Chico (Mercado Chico) a la de Santa Ana a través del nodo del Grande (Mercado Grande), más la rama colateral de la Avenida de Portugal (Villar, 1989: 172). 
Atraída por el ferrocarril, la ciudad burguesa apenas se desarrollará por el frente oriental -San Roque-, a favor de los bonancibles condicionamientos topográficos de la superficie de erosión berroqueña. Esta contenida configuración, a lo largo del tiempo, sufrió una gran transformación desde el momento en el que la ciudad comenzó a experimentar un incremento sustancial de la población (Tabla 1). Fue entonces, al comedio del siglo XX, cuando comenzaron las ampliaciones progresivas y la edificación de nuevos terrenos, cada vez más alejados, destinados a satisfacer la creciente demanda residencial (Tabla 2).

Figura 1. Crecimiento y estructura urbana de Ávila.

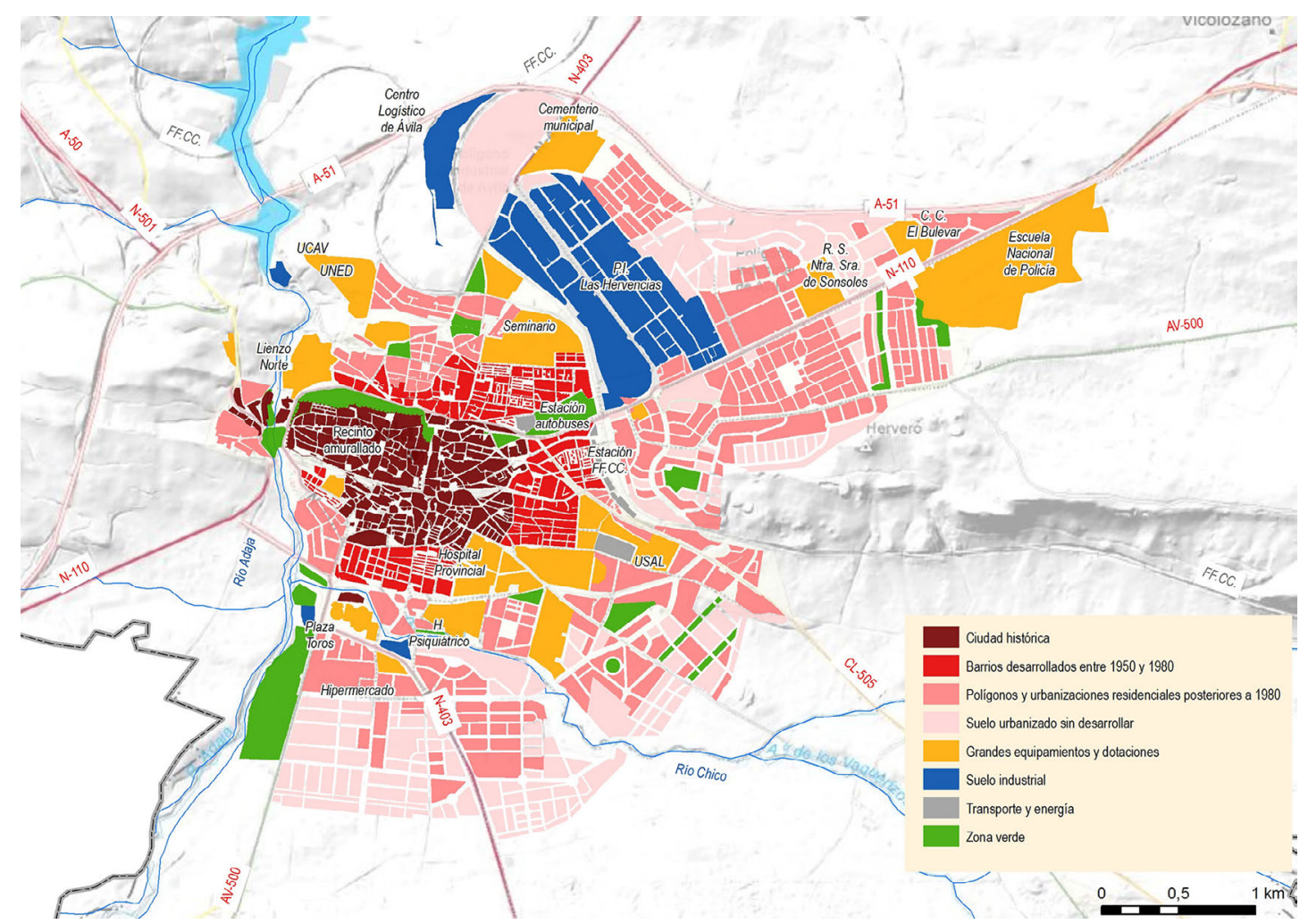

Si en la ciudad histórica, aquejada intensamente por los procesos de abandono comunes a los centros urbanos españoles, la modificación más sustancial será la ocupación selectiva de los escasos espacios que van quedando libres -huertas conventuales, jardines o corrales privados- y la sustitución, renovación, restauración o rehabilitación en su caso, muy parcial, de las bajas edificaciones precedentes por modernos edificios en altura -mediatizados en lo posible por la restricción de volúmenes y la adaptación a la fisonomía del entorno-, la cuantiosa necesidad habitacional registrada en la capital se resolverá, en una primera fase, hasta bien entrado el decenio de los setenta, con la aparición de los nuevos barrios inmediatos a aquella -y su característica tipología constructiva plurifamiliar en bloques o manzanas abiertas, en alturas de tres y cuatro plantas-.

Tabla 1. Evolución de la población residente en el municipio de Ávila entre 1950 y 2013

\begin{tabular}{|c|c|c|c|c|c|c|c|c|}
\hline 1950 & 1960 & 1970 & 1981 & 1991 & 2001 & 2011 & 2012 & 2013 \\
\hline 23.588 & 28.032 & 31.534 & 40.173 & 45.977 & 47.967 & 59.008 & 58.915 & 59.258 \\
\hline
\end{tabular}

Fuente: I.N.E.: Censo de Población y Viviendas (hasta 1991) y Padrón Municipal de Habitantes.

De esta forma, prosiguiendo con el sentido natural en el agrandamiento del solar urbano hacia levante, evitando en lo posible el obstáculo fluvial y los pendientes escarpes del mediodía, al mismo tiempo que se preservan las más valoradas panorámicas de las murallas y su perímetro de lienzo y torres, y hasta llegar a las vías del tren, auténticas barreras para la continuación del desarrollo en este sector, irán surgiendo, o completando su incipiente crecimiento previo, dando acomodo a los relevantes aumentos del vecindario de la época (7.946 y 8.639 habitantes entre 1950 y 1970 y de 1970 y 1981, respectivamente) los barrios de San Antonio-Estación y Santo Tomás. Más lentamente será abierto un nuevo sector de expansión 
urbana en el Sur -con origen en La Toledana y el mismo Santo Tomás-, ya en el fondo de la fosa tectónica y más allá del arrabal de San Nicolás -muy remozado- ${ }^{2}$, que se irá dinamizando hacia el valle del río Chico a medida que se van agotando las posibilidades del avance oriental; y que se erige desde los años ochenta-noventa en la porción urbana que concentra los polígonos residenciales de mayor dinamismo: Valle Amblés-Universidad; soportando en gran medida los incrementos demográficos más notables (7.794 residentes entre 1981 y 2001 y 11.041 más hasta 2011), en una suerte de modernos ensanches de morfología reticular, con elementos residenciales de densidad media en manzana cerrada o bloque, en las proximidades de varios de los principales equipamientos de la capital (Plaza de Toros, Estadio Municipal, Hipermercado, Hospital Provincial, Psiquiátrico, Escuelas Universitaria y Politécnica de la Universidad de Salamanca).

Tabla 2. Número de edificios destinados a vivienda en Ávila por etapa de construcción

\begin{tabular}{|c|c|c|c|c|c|c|c|}
\hline Antes de 1950 & Años 50 & Años 60 & Años 70 & Años 80 & Años 90 & Años 2000 & TOTAL edificios \\
\hline 1.035 & 934 & 621 & 1.182 & 928 & 1.036 & 2.284 & 8.020 \\
\hline
\end{tabular}

Fuente: I.N.E. Censo de Población y Viviendas.

En el extremo contrario, a septentrión, la evolución constructiva de las dos últimas décadas también ha alcanzado al valle del arroyo de Las Pozas, una suave vaguada en la plataforma estructural, que dilata las piezas heredadas de San Antonio-La Cacharra-Encarnación, y que, encorsetado hacia el Norte por la línea férrea a Salamanca, dibuja unas zonas de baja edificabilidad en torno al Seminario y a la Universidad Católica de Ávila y el Centro Asociado de la UNED, donde el adosado ha sido el tipo constructivo predominante. Similares tipologías de residencia unifamiliar en hilera, adosadas o aisladas, se han levantado coetáneamente en algunas urbanizaciones que han ido estirando considerablemente los bordes de la ciudad (téngase en cuenta que 3.320 edificios destinados a vivienda se construyeron entre 1991 y 2011, el 41,4\% de todos los existentes). Una de menor extensión es la aparecida en la otra orilla del Adaja, con vistas al núcleo amurallado. Pero la más significativa es la de Las Hervencias, en la carretera de Villacastín, allende la barrera del ferrocarril y del homónimo polígono industrial de específica localización al lado de la fábrica de Nissan, y cercana a la Residencia Sanitaria Nuestra Señora de Sonsoles, a la Escuela Nacional de Policía y al Centro Comercial "El Bulevar".

\section{DESARROLLO URBANO RECIENTE Y CARACTERÍSTICAS DEMOGRÁFICAS DE LOS DISTINTOS BARRIOS DE LA CIUDAD DE ÁVILA}

La positiva evolución demográfica experimentada por Ávila durante el último decenio examinado, en visos de ralentización actual (250 empadronados más en el término durante el lapso 2011-2013), solamente puede ser explicada, en el marco de la dinámica expansiva conocida por todas las áreas urbanas de Castilla y León, por el aumento del número de residentes en la ciudad compacta, sin contar con ningún municipio periurbano de sobresaliente dinamismo como para absorber en torno a sí las intensas pulsaciones poblacionales conocidas en los primeros años dos mil ${ }^{3}$. Así, con ausencia de crecimientos exógenos de entidad, la capital se desarrollará enormemente en un proceso de ampliación del espacio construido cuyo soporte estratégico se ha fundamentado, además, en la dialéctica establecida entre el centro y la periferia.

Bajo estas pautas, que han caracterizado a Ávila a lo largo de estos diez años finales, se esconden comportamientos muy variables entre los diferentes sectores urbanos que la componen (Figura 2), tanto desde el punto de vista de su evolución y cuantía residencial como de sus principales estructuras de población, en particular las etarias.

En un ejercicio de erudición no exento de riesgos y de limitaciones fruto de la utilización de las unidades estadísticas al uso -distritos y secciones- en la división de los principales segmentos de la ciudad, al hilo también del análisis efectuado sobre la configuración de la misma por la sucesiva adición de

2 Antesala de la ocupación del flanco meridional sobre el Valle de Amblés, de orientación solana y proximidad al rico labradío de la urbe 3 Ávila, tras Burgos, es la ciudad de la Comunidad Autónoma que ha registrado un mayor incremento de población -la que más en términos relativos- entre 2001 y 2011. Con todo, este importante aumento habitacional no es tan destacado dentro del conjunto de las áreas urbanas -ciudad y entorno urbano- castellanas y leonesas, situándose en el quinto puesto, en la línea del acontecido, por ejemplo, en Segovia (1.181 residentes más, pero 9.087 a sumar por los municipios de su dinámico contorno de influencia). 
las áreas/barrios mencionados, que son los comúnmente identificados por los abulenses, seis son las grandes teselas que conforman el espacio urbano de la capital. Dos puede decirse que corresponden estrictamente al "centro" -la ciudad histórica adentro de las murallas y los primigenios arrabales de extramuros-. Los arrabales más alejados de aquella y los barrios que se van adosando durante la etapa del desarrollismo quedan enmarcados como piezas originales en el resto de las zonas. Prima en ellas, pues, una distinción laxa siguiendo exclusivamente un criterio censal de localización, tamaño y proximidad al núcleo central: al Norte y Sur, respectivamente, Encarnación y el variopinto conjunto de San Nicolás-Las Vacas-La Toledana-Valle Amblés. Y más alejadas las misceláneas áreas de Santo Tomás-Universidad, en continuación de la anterior hacia el Sureste y, haciendo lo propio en el Noreste con la primera de estas, La Cacharra-San Antonio-Estación-Las Hervencias.

Figura 2. Sectores urbanos de la ciudad de Ávila.

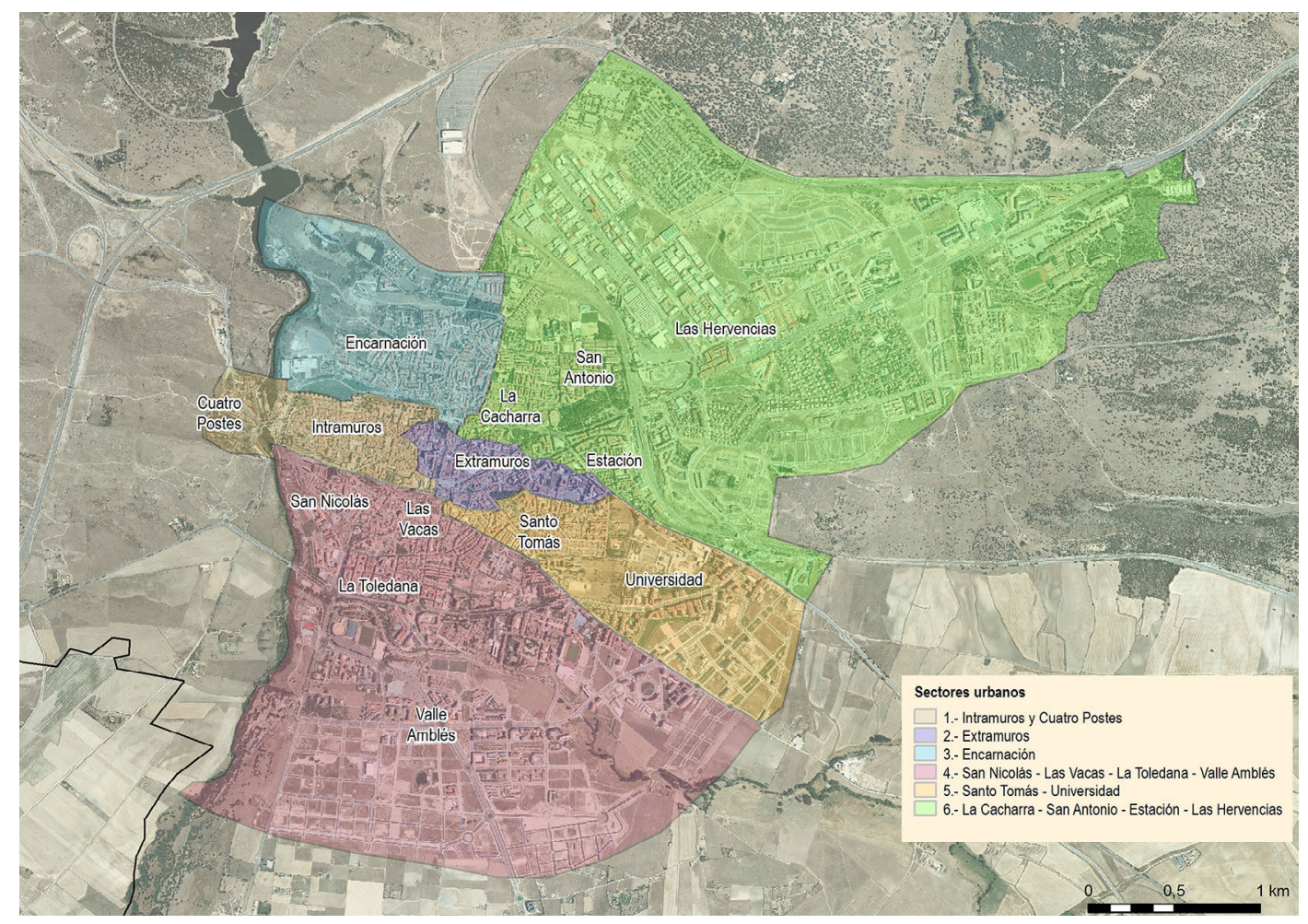

Fuente: I.G.N. y C.N.I.G.: CartoCiudad (sistema de información de la red viaria, cartografia urbana y divisiones censal y postal de España).

La importante capacidad de crecimiento residencial de Ávila en el pasado más inmediato se ha manifestado, en parigual, y como no podía ser de otra manera, en la ampliación del número de secciones censales en los más pujantes de estos distritos. No en vano, a las porciones del Valle Amblés, Universidad y Las Hervencias les han correspondido tres, una y dos, por este orden, nuevas unidades censales. Extensión de los polígonos y urbanizaciones en los sectores de la ciudad más alejados como prueba fehaciente del impulso sobresaliente en los cómputos de población registrados; empero muestra palmaria, no debe obviarse tal circunstancia, de la coexistencia de una serie de fenómenos urbanísticos contradictorios, a través de los cuales se materializan los mecanismos básicos de intervención y creación de ciudad en la actualidad (Calderón, 2001; Martínez y Luengo, 2005).

\subsection{La dialéctica centro-periferia en la explicación de la evolución de la población por sectores urbanos: la impronta de la movilidad residencial intraurbana}

El primero de estos procesos, dilatado en el tiempo, pero de todavía notable intensidad en nuestros días, ha sido el del progresivo abandono y vaciamiento del centro histórico, que deja de ser un ámbito de atractivo residencial, como lo atestigua la perenne reducción de sus vecindarios. Si circunscribiendo el apunte al balance 2004-2012 viven en el conjunto del entramado "medieval" 6.139 personas (el 10,5\% de todos los abulenses), estos continúan mermando en 533. Este es un fenómeno ininterrumpido prác- 
ticamente desde el mismo momento en el que Ávila comienza a agrandarse mediada la anterior centuria. La especialización funcional, la ausencia significativa de espacios libres y las dificultades y trabas -por ausencia de intereses inmobiliarios o de restricciones formales- para la sustitución o renovación del viejo casalicio son las explicaciones más argumentadas. ${ }^{4}$. Otro tanto ocurre en los arrabales y barrios populares desarrollados al ritmo de los fuertes incrementos demográficos de las décadas 50-70 del siglo XX. En ellos, las causas del abandono deben buscarse en factores como la insuficiencia de infraestructuras y equipamientos dotacionales o la peor calidad de las viviendas, ubicadas por lo general en edificios que han cumplido un ciclo de 45-60 años.

La salida del hogar paterno, la mejora del nivel de vida de la población madura-joven en los años previos a la crisis, y las nuevas modas y pautas residenciales acaban por explicar la búsqueda de nuevos espacios donde vivir. Aun así, estos sectores más apegados al casco histórico todavía aglutinan a un alto porcentaje de los habitantes de la capital, si bien los datos concretos son difíciles de precisar en una valoración de conjunto como la realizada nada desdeñable inmigración extranjera ( $10 \%$ de los habitantes de la ciudad).

Frente al descenso generalizado de población en la ciudad tradicional y barrios aledaños, en un contexto de evidente afianzamiento demográfico de Ávila, el crecimiento urbano periférico -que en el caso abulense refuerza el modelo de ciudad compacta central, no se olvide- ha sido verdaderamente espectacular (Tabla 3). En sintonía con lo señalado líneas atrás, el grueso de las 6.506 personas que entre 2004 y 2012 pasan a engrosar las listas padronales lo hacen fundamentalmente en tres sectores urbanos, y, en esencia, en cada una de las seis secciones censales creadas a tal efecto "ex novo" (6.980 censados más). La búsqueda de espacios abiertos, de nuevas tipologías edificatorias o simplemente de inmuebles de calidad, en mayor cuantía y a precios más asequibles que en el "centro", son las razones que se suelen esgrimir a la hora de explicar la atracción de residentes hacia este tipo de áreas -que en el caso de Ávila, se vuelve a repetir, serían los dos grandes segmentos ubicados y expandidos hacia levante a Norte y Sur del espacio nuclear-.

Tabla 3. Distribución de la población por los diferentes sectores urbanos de la ciudad de Ávila* entre 2004 y 2012

\begin{tabular}{|lcc|}
\hline Sector urbano & Población 2004 & Población 2012 \\
Sector 1. Intramuros y Cuatro Postes & 3.263 & 3.062 \\
Sector 2. Extramuros & 3.409 & 3.077 \\
Sector 3. Encarnación & 3.376 & 3.435 \\
Sector 4. San Nicolás-Las Vacas-La Toledana-Valle Amblés & 17.300 & 18.948 \\
Sector 5. Santo Tomás-Universidad & 8.683 & 10.975 \\
Sector 6. La Cacharra-San Antonio-Estación-Las Hervencias & 15.648 & 18.688 \\
TOTAL & 51.679 & 58.185 \\
'No se incluyen los residentes en el resto de entidades de población del término municipal. & \\
\hline
\end{tabular}

Fuente: Ayuntamiento de Ávila: Explotación estadística del Padrón Municipal.

Dicotomía centro/periferia, como contraste evidente entre la ciudad tradicional -casco histórico más barrios- y la "moderna" ciudad ensanchada -la finisecular y la del boom inmobiliario-, que se traduce de la misma manera en unas desiguales estructuras por edad, mucho más envejecidas (a la par de feminizadas) en el primero de estos ámbitos.

\subsection{El envejecimiento como rasgo demográfico fundamental en la diferenciación espacial de la ciudad de Ávila}

La mera contemplación de las pirámides demográficas (Figura 3), y de las cifras que de su manipulación se desprenden (Tabla 4), dan buena cuenta de esta afirmación. A través de ellas se percibe un doble proceso de senescencia, tanto por la cúspide como por la base de las pirámides de población, en la ciudad histórica, y muy especialmente en su sector de Extramuros. Esto se debe a la escasa proporción de jóve-

\footnotetext{
4 La creciente terciarización y recualificación de las funciones tradicionales del centro histórico, cada vez más impregnado de una cultura museística que pretende hacer de él una ciudad-patrimonio para el turista, la ausencia de una adecuada política pública de recuperación del tejido edificado, que pudiera paliar el estado lamentable en el que se encuentran muchos de los inmuebles, y la carencia de inversión privada, que hace que las escasas viviendas renovadas o rehabilitadas alcancen precios astronómicos, acaban erigiéndose como los factores explicativos de la pérdida de importancia residencial del "centro" (Villar, 1999).

5 Incluso los correspondientes a Encarnación, uno de estos barrios mejor individualizado por la estadística, están ocultos tras las altas residenciales habidas en las novedosas promociones de su entorno.
} 
nes ( $12,93 \%$ y $11,44 \%$, en el recinto amurallado y el arrabal externo, respectivamente) y a la importancia relativa de los escalones correspondientes a la población anciana (20,53\% y 30,55\%). Son, junto con el sector 6 -el segundo más sobre envejecido, por cierto-, dado el peso que dentro de él tienen los barrios más populares de La Cacharra, San Antonio y Estación, contrarrestado solo en parte por Las Hervencias, las teselas urbanas que presentan, entre otros expresivos indicadores, las tasas e índices de vejez en valores por encima de las medias marcadas por el conjunto de la ciudad $(16,95 \%$ y 1,08$)$.

Figura 3. Pirámides de población de los diferentes sectores urbanos en 2012.

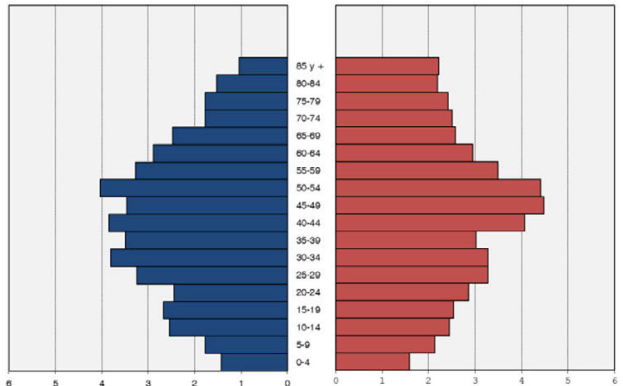

Sector 1

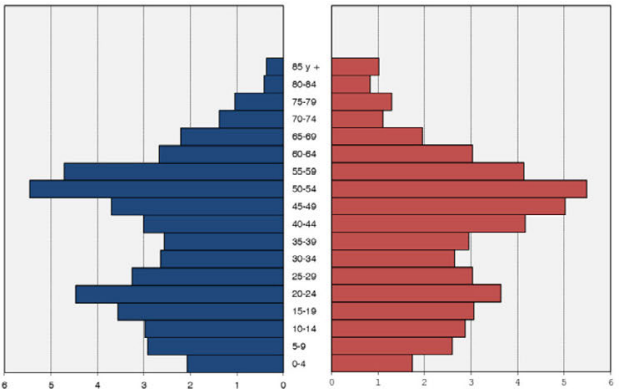

Sector 3

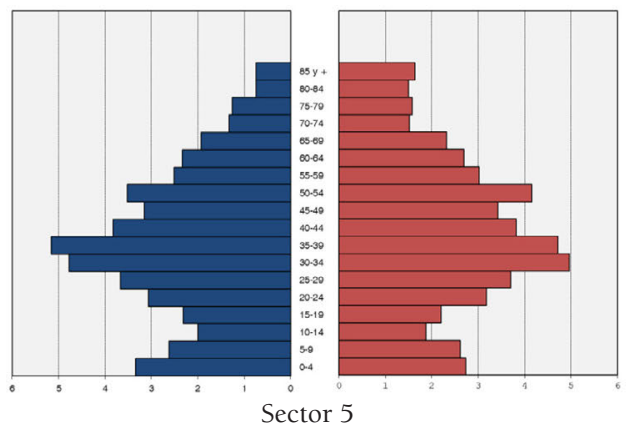

Fuente: Ayuntamiento de Ávila: Explotación estadística del Padrón Municipal.

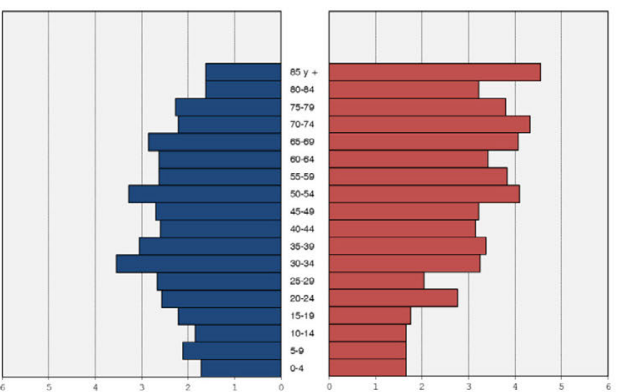

Sector 2

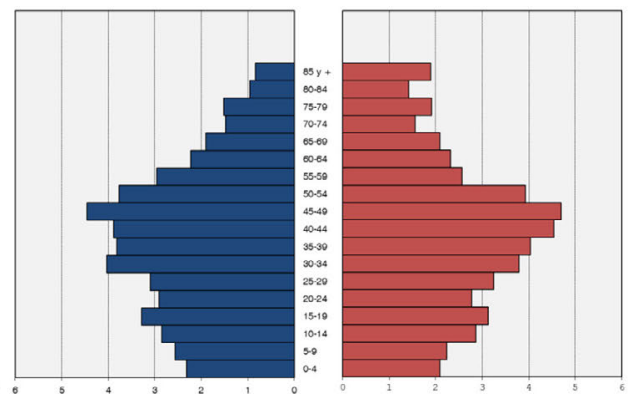

Sector 4

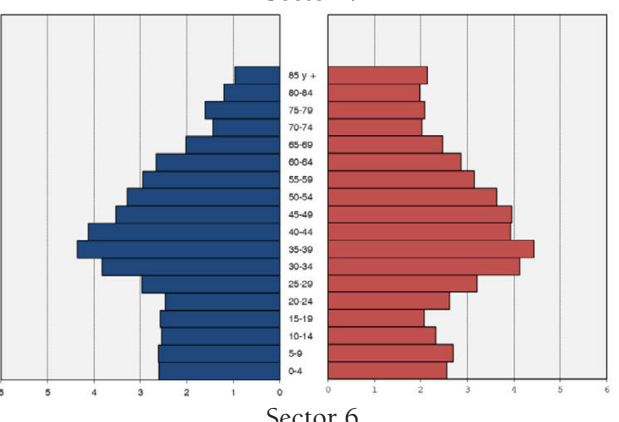

Tabla 4. Principales indicadores de estructuras demográficas por edad en los diferentes sectores urbanos de la ciudad de Ávila en 2012

\begin{tabular}{|c|c|c|c|c|c|c|c|}
\hline $\begin{array}{l}\text { Sector } \\
\text { urbano }\end{array}$ & $\begin{array}{c}\text { Índice de } \\
\text { envejecimiento }\end{array}$ & $\begin{array}{c}\text { Tasa de } \\
\text { envejecimiento }\end{array}$ & $\begin{array}{c}\text { Tasa de sobre } \\
\text { envejecimiento }\end{array}$ & $\begin{array}{c}\% \text { de } \\
\text { octogenarios }\end{array}$ & Edad media & $\begin{array}{l}\text { Proporción } \\
\text { de activos }\end{array}$ & $\begin{array}{c}\text { Índice de } \\
\text { reemplazo de activos }\end{array}$ \\
\hline Sector 1 & 1,59 & 20,53 & 34,06 & 6,99 & 44,46 & 66,54 & 0,89 \\
\hline Sector 2 & 2,67 & 30,55 & 36,06 & 11,02 & 48,76 & 58,01 & 0,66 \\
\hline Sector 3 & 0,71 & 11,61 & 22,57 & 2,62 & 39,99 & 71,95 & 1,16 \\
\hline Sector 4 & 0,97 & 15,58 & 32,82 & 5,11 & 40,73 & 68,28 & 1,41 \\
\hline Sector 5 & 0,91 & 14,58 & 31,81 & 4,64 & 39,94 & 69,38 & 0,90 \\
\hline Sector 6 & 1,10 & 17,94 & 35,07 & 6,29 & 41,99 & 65,78 & 0,84 \\
\hline Ávila & 1,08 & 16,95 & 33,37 & 5,66 & 41,63 & 67,29 & 1,03 \\
\hline
\end{tabular}

Fuente: Ayuntamiento de Ávila: Explotación estadística del Padrón Municipal. 
Por el contrario, las unidades que capitalizan las progresiones inmobiliarias más contemporáneas -al margen de Las Hervencias- se confirman como los sectores donde la presencia de personas adultas -en edad activa, por consiguiente- y menores de 16 años es más elevada. En este sentido, es Encarnación, curiosamente, como gozne entre la "vieja" y la "nueva" ciudad, la pieza urbana que arroja los datos de un horizonte demográfico más alentador, presentando la relación de mayores y jóvenes -índice de envejecimiento- más contenida: 0,71. En una tónica parecida de marcadores "poco" envejecidos, los sectores 4 y 5 , los que se despliegan por toda la zona sur, en la charnela también entre los dos grandes dominios de la capital, logran equilibrar favorablemente las diferentes cohortes etarias; bien es cierto que mientras en el caso de San Nicolás-Las Vacas-La Toledana-Valle Amblés el reemplazo de población activa está asegurado -con un índice del 1,41, el más alto de toda la ciudad-, en el de Santo Tomás-Universidad este es más que cuestionable $(0,90)$, al no estar garantizado para el futuro próximo ese relevo generacional en la fuerza de trabajo, como consecuencia de la mayor presencia de población madura próxima a la edad jubilar (60-64 años) que de adultos-jóvenes de entre 15 y 19 años, los próximos en incorporarse potencialmente al mercado laboral.

\section{LAS VARIABLES DE LA DINÁMICA POBLACIONAL Y SU PROYECCIÓN URBANA}

\subsection{Los desajustes con el modelo de crecimiento residencial planeado}

A lo largo de más de sesenta años, la transformación espacial de Ávila se ha producido al compás que han marcado las dinámicas poblacionales. Del pequeño núcleo originario, en torno al casco medieval -intramuros y extramuros- se pasó, sin solución de continuidad, a una ciudad que se expandía, más allá de los límites históricos, por una serie de barrios que iban surgiendo al socaire del desarrollo migratorio procedente de la provincia y, sobremanera, del medio rural circundante (16.585 personas). La atracción urbana y el tímido apogeo de unas actividades que demandaban mano de obra propiciaron la temprana colmatación residencial -decenio del 50 a los 70- de las zonas adosadas al "centro" de la capital (2.737 edificios destinados a vivienda fueron construidos en esa época). Desde los años ochenta, la potenciación de las bases económicas a partir del estímulo del turismo, las mejoras de la función administrativa y comercial y el impulso de la producción industrial, unidas al hecho natural de la emancipación y reproducción de parte de la abundante población en edades y situación de hacerlo -generaciones del baby boom de los sesenta y primeros setenta-, y a pesar de las regresiones habidas en los saldos vegetativos durante los noventa, contribuyeron como factores de consuno a la expansión (7.794 habitantes y 1.964 edificios levantados) de la Ávila finisecular (Tabla 5).

Tabla 5. Número de viviendas en Ávila por etapa de construcción y tipo de uso actual

\begin{tabular}{|lcccccccc|}
\hline & Antes de 1950 & Años 50 & Años 60 & Años 70 & Años 80 & Años 90 & Años 2000 & TOTAL ciudad \\
Principales & 2.999 & 2.082 & 2.314 & 4.827 & 3.169 & 3.075 & 4.304 & 22.770 \\
Secundarias & 347 & 485 & 411 & 594 & 288 & 394 & 987 & 3.506 \\
Vacías & 510 & 912 & 698 & 1.212 & 369 & 425 & 4.063 & 8.189 \\
TOTAL & 3.856 & 3.479 & 3.423 & 6.633 & 3.826 & 3.894 & 9.354 & 34.465 \\
\hline
\end{tabular}

Fuente: I.N.E. Censo de Población y Viviendas.

Una ampliación de la ciudad que no ha conocido límites durante la primera década del siglo XXI: 11.041 habitantes y 2.284 nuevas edificaciones; en un ensanchamiento del perímetro urbanizado sin precedentes, dadas las bajas densidades medias de ocupación habitacional de las modernas promociones de vivienda (Figura 4). La movilidad residencial hacia la periferia, que en el caso que nos ocupa no hace sino reforzar el modelo de ciudad compacta, sin los efectos de difusión conocidos en las áreas urbanas del presente, no es óbice para que Ávila manifieste las contradicciones del crecimiento residencial efectuado -siguiendo, además, esa estrategia decidida de abandono de los espacios tradicionales-. Así son los trazos actuales de la "ciudad del boom inmobiliario", la que, por encima de las necesidades reales -demanda efectiva-, que vienen marcadas por las pulsaciones poblacionales, se dimensiona desorbitadamente en función de una conjunción de intereses urbanísticos totalmente lastrados, a la postre, por la crisis que vivimos (Serrano, 2004 y 2010).

Nunca antes en la historia de la ciudad se han construido tantas viviendas, ni tantas de ellas permanecen vacías (y sin vender, como lo atestigua el balance de transacciones inmobiliarias del Ministerio de Fomento). Al significativo número de las alojadas en el casco y en los bloques levantados en los barrios más populares -en esa suerte de trasvase residencial intraurbano-, el último decenio concluido arroja resultados verdaderamente elocuentes: el 46\% de la producción inmobiliaria de esos años se encuentra desocupada. Y ello en una 
década, bien es cierto, de importancia en lo que a afianzamiento del vecindario se refiere. Un periodo en el que cobran fuerza tanto las ganancias por movimientos migratorios como por la propia dinámica positiva del crecimiento vegetativo de la población (Figura 5). Los unos engrosados, aunque no exclusivamente, por los importantes flujos de inmigrantes extranjeros llegados a la capital -tan relevantes en el sostén de la actividad económica y la renovación de las estructuras demográficas- (4.057 entre 2004 y 2013); en franca y progresiva ralentización desde 2008, pero que han proseguido paliando numéricamente a los abulenses (autóctonos o previamente ya empadronados) que se marchan (Tabla 6). Y unos saldos naturales favorables siempre a tenor de las más altas tasas de natalidad que de mortalidad registradas (crecimiento vegetativo del $0,16 \%$ en 2012), gracias a una fecundidad -número de hijos por mujer- relativamente elevada: 1,40 (por 1,22 en el caso de la provincia, 1,17 en el de la Comunidad y 1,32 en el conjunto de España).

Figura 4. Evolución reciente de la superficie urbanizada en la ciudad de Ávila entre 1997 y 2008.

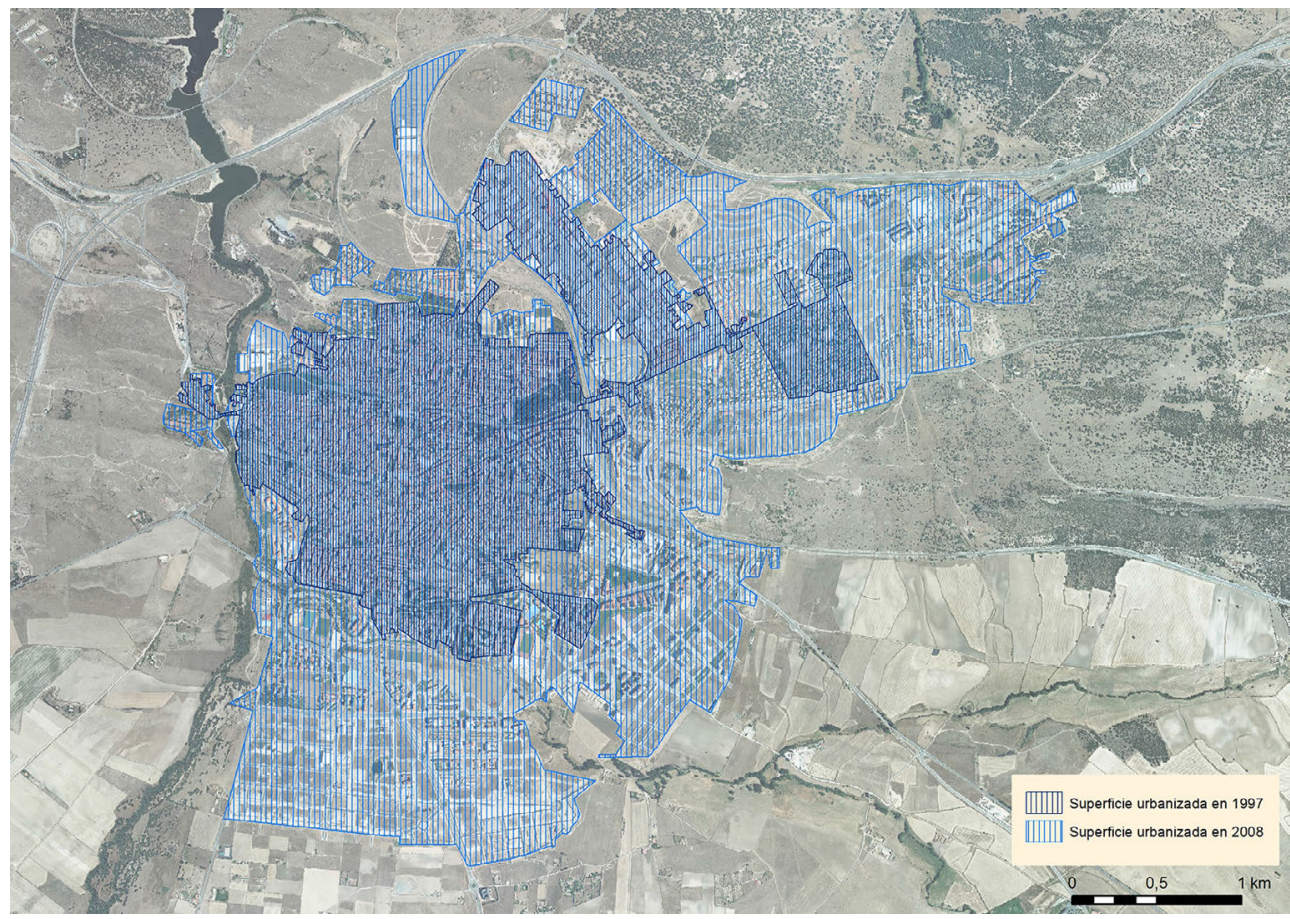

Figura 5. Evolución de la dinámica natural de la población en Ávila capital.

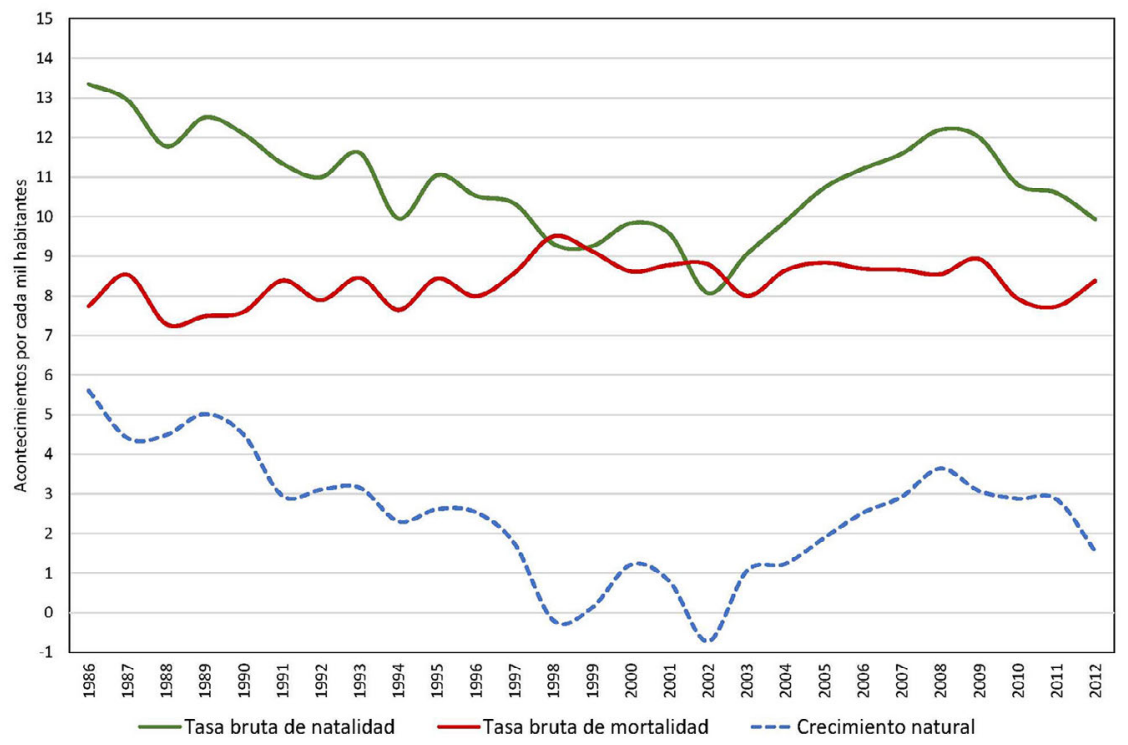

Fuente: I.N.E. Movimiento Natural de la Población y SIE (Almacén de datos multidimensional de la Junta de Castilla y León). 
Tabla 6. Movimientos migratorios en Ávila capital entre 2005 y 2012

\begin{tabular}{|ccccccc|}
\hline \multirow{2}{*}{ Año } & \multicolumn{2}{c}{ Migraciones interiores (dentro de España) } & \multicolumn{3}{c|}{ Migraciones exteriores (internacionales) } \\
& Saldo & Inmigraciones & Emigraciones & Saldo & Inmigraciones & Emigraciones \\
2005 & 486 & 1.675 & 1.189 & 775 & 786 & 11 \\
2006 & 354 & 1.913 & 1.559 & 1.044 & 1.062 & 18 \\
2007 & 435 & 2.187 & 1.752 & 1.565 & 1.633 & 68 \\
2008 & -24 & 1.526 & 1.550 & 770 & 842 & 72 \\
2009 & 129 & 1.718 & 1.589 & 424 & 628 & 204 \\
2010 & -187 & 1.562 & 1.749 & 391 & 484 & 93 \\
2011 & -171 & 1.592 & 1.763 & 324 & 375 & 51 \\
2012 & -460 & 678 & 1.138 & 220 & 278 & 58 \\
\hline El número de migrantes cuantifica el total de altas y bajas padronales derivadas de cambios de residencia, por lo que \\
incluye cualquier tipo de migraciones interiores entre municipios.
\end{tabular}

Fuente: I.N.E. Estadística de Variaciones Residenciales.

La Ávila contemporánea se fragua al calor de las disposiciones contempladas en el Plan General de Ordenación Urbana de 1998, prolongado en su fundamentación de asociar una alta disponibilidad de suelo urbanizable a la mejora de la capacidad de acceso a la vivienda por la Adaptación-Revisión de 2005, que es el instrumento de planeamiento vigente (tras siete modificaciones) a día de hoy. Entre 1998 y 2004 se desarrollan 22 de los 40 planes parciales previstos, construyéndose 11.253 viviendas, la mitad de las proyectadas, pero mucho más de las necesarias, ya que en ese lapso de tiempo la ciudad se incrementó en 4.676 habitantes (Calderón, 2012 y 2013) (Tabla 7). En 2005 se delimitarían otros 18 nuevos sectores de suelo urbanizable -y uno aparte en Vicolozano como ampliación del polígono industrial-, con capacidad, nada más ni nada menos, para 11.560 viviendas (manteniéndose a su vez el propósito de edificar las 10.500 que quedaban pendientes), esgrimiéndose la máxima de no introducir incertidumbre entre unos agentes -promotores, constructores y financiadores- activos e implicados en plena vorágine de optimismo urbanizador (Rivas, 2007).

Tabla 7. Ávila: previsiones y grado de ejecución del PGOU de 1998 en 2005

\begin{tabular}{|ccccc|}
\hline Usos del suelo & \multicolumn{2}{c}{ Previsiones PGOU 1998 } & Desarrollado (en 2004) & Pendiente \\
& Superficie $\left(\mathrm{m}^{2}\right)$ & 1.344 .142 & 666.990 & 471.938 \\
Suelo Urbano No Consolidado & $\mathrm{N}^{\circ}$ máximo de viviendas & 2.300 & 719 & 1.060 \\
& Superficie $\left(\mathrm{m}^{2}\right)$ & 5.553 .531 & 2.319 .224 & 2.780 .141 \\
Suelo Urbanizable Delimitado & $\mathrm{N}$ máximo de viviendas & 20.513 & 10.013 & 10.500 \\
\hline
\end{tabular}

Fuente: CALDERÓN CALDERÓN, B. (2012): “Áreas urbanas y estructura de las ciudades de Castilla y León”, Población y poblamiento en Castilla y León, p. 799.

Tras el estallido de la "burbuja" inmobiliaria, la ciudad prepara su futuro de la mano de una nueva herramienta planificadora -en estado de Avance- que estima una población horizonte en 2030 de 100.000 habitantes (recogiendo la idea del "Plan 100.000" esbozada por el Plan Estratégico de Desarrollo Industrial de la Ciudad de Ávila, lanzado en 2006) y hasta 11.000 nuevas viviendas -además de un nuevo espacio industrial junto a la autovía a Salamanca, otro hospital, un tercer centro comercial, el recinto ferial, entre otras actuaciones de calado-, que se añadirían a las 8.189 desocupadas según censo del 2011. Una visión harto generosa, a nuestro juicio, por cuanto la progresión demográfica da señales de agotamiento y de un cambio de tendencia que en el mejor de los escenarios proyectados situaría el contingente poblacional de la capital, para 2027, en 60.325 habitantes -bajando en la hipótesis más factible a los 54.390-.

\subsection{Proyección a corto y medio plazo de la población de Ávila capital}

La proyección se basa en el método de los componentes múltiples (mortalidad, fecundidad y migraciones), considerando tres escenarios alternativos. Con el objetivo de hacer una comparación con otras proyecciones, entre 2012 y 2022 el Escenario 1 implica un aumento de la población del 0,4\%, el Escenario 2 del 2,1\% y el Escenario 3 un descenso del 4,4\% (Figura 6). Las proyecciones a corto plazo del Instituto Nacional de Estadística estiman, para el conjunto de la provincia de Ávila, un descenso durante el mismo periodo del $10 \%$. 
Figura 6. Proyección de la población de Ávila capital.

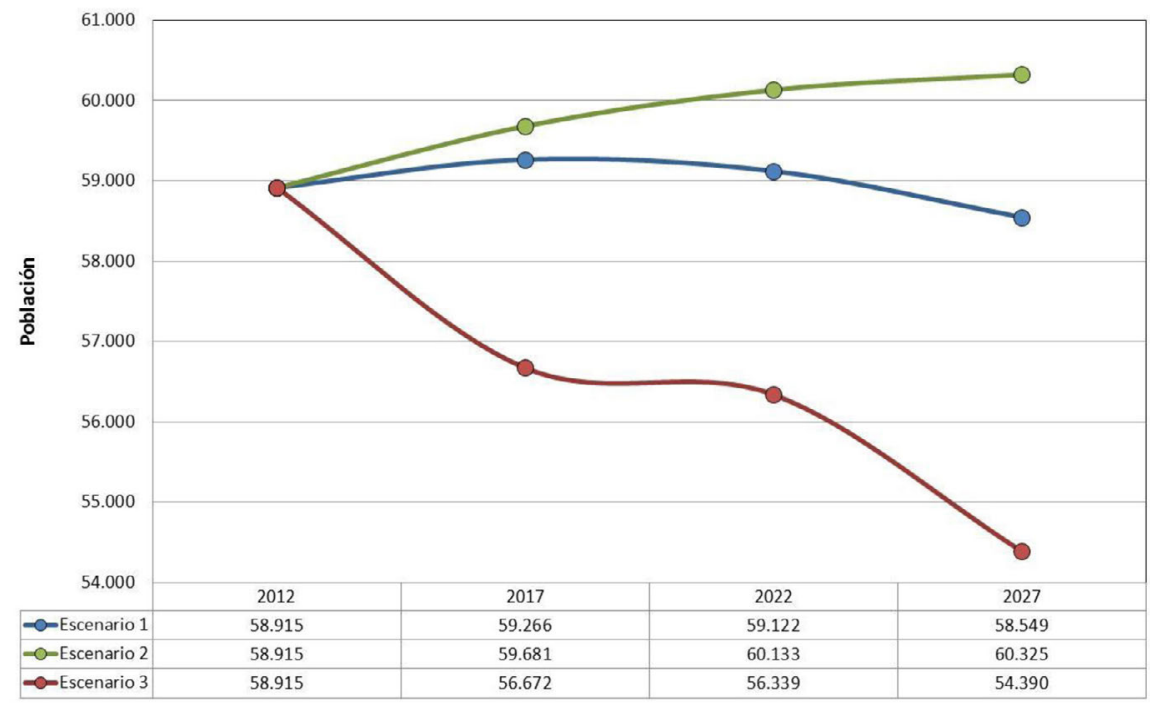

\subsubsection{Escenario 1 (Tablas 8, 9, 10, 11 y Figura 7):}

- Mantenimiento de las probabilidades de defunción y de las perspectivas de paso entre cohortes etarias existentes durante el quinquenio 2007-2012 (esperanza media de vida al nacer constante).

- Mantenimiento de las tasas de fecundidad existentes durante el quinquenio 2007-2012.

- Ausencia de movimientos migratorios.

Tabla 8. Tabla de mortalidad del momento de Ávila capital, 2007-2012

\begin{tabular}{|c|c|c|c|c|c|c|c|c|c|c|}
\hline \multirow[b]{2}{*}{ Edad } & \multicolumn{2}{|c|}{$1_{x}$} & \multicolumn{2}{|c|}{${ }_{5} q_{x}$} & \multicolumn{2}{|c|}{${ }_{5} L_{x}$} & \multicolumn{2}{|c|}{${ }_{5} T_{x}$} & \multicolumn{2}{|c|}{$e_{x}$} \\
\hline & Varones & Mujeres & Varones & Mujeres & Varones & Mujeres & Varones & Mujeres & Varones & Mujeres \\
\hline 0 & 100.000 & 100.001 & 3,13 & 9,90 & 498.906 & 496.540 & 7.944 .314 & 8.504 .428 & 79,44 & 85,04 \\
\hline 5 & 99.687 & 99.011 & 0,00 & 0,00 & 498.436 & 495.055 & 7.445 .408 & 8.007 .888 & 74,69 & 80,88 \\
\hline 10 & 99.687 & 99.011 & 0,00 & 0,71 & 498.436 & 494.879 & 6.946 .972 & 7.512 .833 & 69,69 & 75,88 \\
\hline 15 & 99.687 & 98.941 & 0,61 & 1,97 & 498.284 & 494.216 & 6.448 .535 & 7.017 .953 & 64,69 & 70,93 \\
\hline 20 & 99.626 & 98.746 & 1,69 & 0,00 & 497.712 & 493.729 & 5.950 .251 & 6.523 .738 & 59,73 & 66,07 \\
\hline 25 & 99.458 & 98.746 & 2,41 & 1,95 & 496.693 & 493.248 & 5.452 .540 & 6.030 .009 & 54.82 & 61,07 \\
\hline 30 & 99.219 & 98.554 & 4,22 & 2,56 & 495.047 & 492.136 & 4.955 .847 & 5.536 .761 & 49,95 & 56,18 \\
\hline 35 & 98.800 & 98.301 & 3,54 & 1,29 & 493.126 & 491.188 & 4.460 .800 & 5.044 .624 & 45,15 & 51,32 \\
\hline 40 & 98.450 & 98.174 & 6,30 & 2,97 & 490.702 & 490.143 & 3.967 .674 & 4.553 .436 & 40,30 & 46,38 \\
\hline 45 & 97.830 & 97.883 & 10,04 & 9,48 & 486.696 & 487.094 & 3.476 .972 & 4.063 .293 & 35,54 & 41,51 \\
\hline 50 & 96.848 & 96.955 & 22,62 & 9,94 & 478.764 & 482.365 & 2.990 .276 & 3.576 .198 & 30,88 & 36,89 \\
\hline 55 & 94.657 & 95.991 & 37,00 & 16,21 & 464.532 & 476.065 & 2.511 .512 & 3.093 .833 & 26,53 & 32,23 \\
\hline 60 & 91.155 & 94.435 & 47,61 & 17,24 & 444.927 & 468.104 & 2.046 .980 & 2.617 .768 & 22,46 & 27,72 \\
\hline 65 & 86.816 & 92.807 & 65,18 & 31,55 & 419.932 & 456.713 & 1.602 .053 & 2.149 .665 & 18,45 & 23,16 \\
\hline 70 & 81.157 & 89.879 & 97,14 & 45,55 & 386.076 & 439.158 & 1.182 .122 & 1.692 .951 & 14,57 & 18,84 \\
\hline 75 & 73.273 & 85.785 & 194,78 & 109,06 & 330.687 & 405.534 & 796.045 & 1.253 .793 & 10,86 & 14,62 \\
\hline 80 & 59.001 & 76.429 & 335,30 & 168,88 & 245.550 & 349.876 & 465.358 & 848.260 & 7,89 & 11,10 \\
\hline 85 & 39.218 & 63.521 & 495,53 & 318,73 & 147.507 & 266.992 & 219.809 & 498.384 & 5,60 & 7,85 \\
\hline 90 & 19.784 & 43.275 & 773,89 & 568,51 & 60.645 & 154.871 & 72.302 & 231.392 & 3,65 & 5,35 \\
\hline 95 & 4.473 & 18.673 & 969,33 & 698,56 & 11.527 & 60.754 & 11.657 & 76.522 & 2,61 & 4,10 \\
\hline 100 & 137 & 5.629 & $1.448,50$ & 943,19 & 131 & 15.767 & 131 & 15.767 & 0,95 & 2,80 \\
\hline
\end{tabular}

Tabla 9. Tabla de mortalidad modelo para Ávila capital, 2007-2012

\begin{tabular}{|c|c|c|c|c|c|c|c|c|c|c|}
\hline \multirow{2}{*}{ Edad } & \multicolumn{2}{|c|}{1} & \multicolumn{2}{|c|}{${ }_{5} q_{x}$} & \multicolumn{2}{|c|}{${ }_{5} L_{x}$} & \multicolumn{2}{|c|}{${ }_{5} T_{x}$} & \multicolumn{2}{|c|}{$e_{x}$} \\
\hline & Varones & Mujeres & Varones & Mujeres & Varones & Mujeres & Varones & Mujeres & Varones & Mujeres \\
\hline 0 & 100.000 & 100.001 & 3,37 & 2,81 & 99.697 & 99.748 & 7.949 .485 & 8.522 .925 & 79,49 & 85,23 \\
\hline 1 & 99.663 & 99.720 & 1,41 & 1,20 & 398.286 & 398.568 & 7.849 .789 & 8.423 .177 & 78,76 & 84,47 \\
\hline 5 & 99.522 & 99.600 & 0,20 & 0,15 & 497.560 & 497.964 & 7.451 .503 & 8.024 .609 & 74,87 & 80,57 \\
\hline 10 & 99.502 & 99.585 & 0,20 & 0,13 & 497.459 & 497.895 & 6.953 .943 & 7.526 .645 & 69,89 & 75,58 \\
\hline 25 & 99.482 & 99.573 & 1,52 & 0,57 & 497.029 & 497.723 & 6.456 .484 & 7.028 .749 & 64,90 & 70,59 \\
\hline 20 & 99.330 & 99.516 & 3,64 & 1,13 & 495.746 & 497.302 & 5.959 .455 & 6.531 .027 & 60,00 & 65,63 \\
\hline 25 & 98.968 & 99.404 & 4,42 & 1,50 & 493.749 & 496.650 & 5.463 .709 & 6.033 .725 & 55,21 & 60,70 \\
\hline 30 & 98.531 & 99.256 & 3,86 & 1,68 & 491.705 & 495.861 & 4.969 .960 & 5.537 .075 & 50,44 & 55,79 \\
\hline 35 & 98.151 & 99.089 & 4,44 & 2,22 & 489.665 & 494.894 & 4.478 .255 & 5.041 .214 & 45,63 & 50,88 \\
\hline 40 & 97.715 & 98.869 & 6,93 & 3,48 & 486.880 & 493.483 & 3.988 .590 & 4.546 .321 & 40,82 & 45,98 \\
\hline 45 & 97.037 & 98.524 & 10,85 & 5,36 & 482.554 & 491.301 & 3.501 .710 & 4.052 .838 & 36,09 & 41,14 \\
\hline 50 & 95.984 & 97.996 & 20,79 & 9,44 & 474.932 & 487.688 & 3.019 .156 & 3.561 .537 & 31,45 & 36,34 \\
\hline 55 & 93.989 & 97.071 & 26,45 & 11,84 & 463.729 & 482.484 & 2.544 .225 & 3.073 .869 & 27,07 & 31,67 \\
\hline 60 & 91.503 & 95.922 & 40,92 & 17,82 & 448.154 & 475.339 & 2.080 .496 & 2.591 .384 & 22,74 & 27,02 \\
\hline
\end{tabular}




\begin{tabular}{|cccccccccc|c|}
65 & 87.759 & 94.213 & 61,25 & 26,15 & 425.355 & 464.907 & 1.632 .342 & 2.116 .045 & 18,60 & 22,46 \\
70 & 82.383 & 91.750 & 101,12 & 47,48 & 391.090 & 447.857 & 1.206 .987 & 1.651 .138 & 14,65 & 18,00 \\
75 & 74.052 & 87.393 & 192,64 & 102,32 & 334.599 & 414.610 & 815.898 & 1.203 .281 & 11,02 & 13,77 \\
80 & 59.787 & 78.451 & 331,56 & 212,69 & 249.380 & 350.541 & 481.298 & 788.671 & 8,05 & 10,05 \\
85 & 39.965 & 61.766 & 509,83 & 384,97 & 148.885 & 249.382 & 231.919 & 438.130 & 5,80 & 7,09 \\
90 & 19.589 & 37.987 & 686,09 & 596,57 & 64.347 & 133.282 & 83.034 & 188.748 & 4,24 & 4,97 \\
95 & 6.149 & 15.325 & 843,91 & 788,87 & 17.773 & 46.402 & 18.687 & 55.466 & 3,04 & 3,62 \\
100 & 960 & 3.236 & $1.000,00$ & $1.000,00$ & 914 & 9.063 & 914 & 9.063 & 0,95 & 2,80 \\
\hline
\end{tabular}

Tabla 10. Cálculo del número de nacimientos con fecundidad constante

\begin{tabular}{|c|c|c|c|c|c|c|}
\hline \multirow{2}{*}{ Edad } & \multirow{2}{*}{${ }_{5} f_{x}$} & \multirow{2}{*}{$\sum_{5} f_{x}$} & \multicolumn{3}{|c|}{ Mujeres } & \multirow{2}{*}{ Nacimientos } \\
\hline & & & 2012 & 2017 & Promedio & \\
\hline 15-19 & 11,96 & 59,80 & 1.480 & 1.425 & 1.452 & 17 \\
\hline $20-24$ & 28,99 & 204,76 & 1.683 & 1.479 & 1.581 & 46 \\
\hline $25-29$ & 60,68 & 508,17 & 1.913 & 1.681 & 1.797 & 109 \\
\hline $30-34$ & 109,30 & $1.054,68$ & 2.350 & 1.910 & 2.130 & 233 \\
\hline $35-39$ & 74,38 & $1.426,56$ & 2.437 & 2.345 & 2.391 & 178 \\
\hline $40-44$ & 12,32 & $1.488,14$ & 2.408 & 2.430 & 2.419 & 30 \\
\hline $45-49$ & 1,41 & $1.495,18$ & 2.447 & 2.397 & 2.422 & 3 \\
\hline \multicolumn{2}{|c|}{ ISF $2012-2016$} & 1,50 & \multicolumn{3}{|c|}{ Nacimientos anuales } & 616 \\
\hline \multicolumn{2}{|c|}{ Nacimientos 2012-2016 } & 3.081 & Varones & 1.577 & Mujeres & 1.503 \\
\hline
\end{tabular}

\begin{tabular}{|c|c|c|c|c|c|c|}
\hline \multirow{2}{*}{ Edad } & \multirow{2}{*}{${ }_{5} f_{x}$} & \multirow{2}{*}{$\sum_{5} f_{x}$} & \multicolumn{3}{|c|}{ Mujeres } & \multirow{2}{*}{ Nacimientos } \\
\hline & & & 2017 & 2022 & Promedio & \\
\hline $15-19$ & 11,96 & 59,80 & 1.425 & 1.437 & 1.431 & 17 \\
\hline $20-24$ & 28,99 & 204,76 & 1.479 & 1.423 & 1.451 & 42 \\
\hline $25-29$ & 60,68 & 508,17 & 1.681 & 1.477 & 1.579 & 96 \\
\hline $30-34$ & 109,30 & $1.054,68$ & 1.910 & 1.678 & 1.794 & 196 \\
\hline $35-39$ & 74,38 & $1.426,56$ & 2.345 & 1.906 & 2.126 & 158 \\
\hline $40-44$ & 12,32 & $1.488,14$ & 2.430 & 2.339 & 2.384 & 29 \\
\hline $45-49$ & 1,41 & $1.495,18$ & 2.397 & 2.419 & 2.408 & 3 \\
\hline \multicolumn{2}{|c|}{ ISF $2017-2012$} & 1,50 & \multicolumn{3}{|c|}{ Nacimientos anuales } & 542 \\
\hline \multicolumn{2}{|c|}{ Nacimientos 2017-2021 } & 2.710 & Varones & 1.387 & Mujeres & 1.322 \\
\hline
\end{tabular}

\begin{tabular}{|c|c|c|c|c|c|c|}
\hline Edad & ${ }_{5} \mathbf{f}_{\mathrm{x}}$ & $\sum_{5} f_{x}$ & \multicolumn{3}{|c|}{ Mujeres } & Nacimientos \\
\hline 15-19 & 11,96 & 59,80 & 1.437 & 1.347 & 1.392 & 17 \\
\hline $20-24$ & 28,99 & 204,76 & 1.423 & 1.436 & 1.430 & 41 \\
\hline $25-29$ & 60,68 & 508,17 & 1.477 & 1.421 & 1.449 & 88 \\
\hline $30-34$ & 109,30 & $1.054,68$ & 1.678 & 1.474 & 1.576 & 172 \\
\hline $35-39$ & 74,38 & $1.426,56$ & 1.906 & 1.675 & 1.791 & 133 \\
\hline $40-44$ & 12,32 & $1.488,14$ & 2.339 & 1.901 & 2.120 & 26 \\
\hline $45-49$ & 1,41 & $1.495,18$ & 2.419 & 2.328 & 2.374 & 3 \\
\hline \multicolumn{2}{|c|}{ ISF $2022-2026$} & 1,50 & \multicolumn{3}{|c|}{ Nacimientos anuales } & 481 \\
\hline
\end{tabular}

Tabla 11. Evolución de la pirámide de población de Ávila capital en ausencia de migraciones

\begin{tabular}{|c|c|c|c|c|c|c|c|c|c|c|}
\hline \multirow{2}{*}{ Edad } & \multicolumn{2}{|c|}{${ }_{5} S_{x}$} & \multicolumn{2}{|c|}{2012} & \multicolumn{2}{|c|}{2017} & \multicolumn{2}{|c|}{2022} & \multicolumn{2}{|c|}{2027} \\
\hline & Varones & Mujeres & Varones & Mujeres & Varones & Mujeres & Varones & Mujeres & Varones & Mujeres \\
\hline Ntos-0 & 0,99596 & 0,99663 & & & & & & & & \\
\hline $0-4$ & 0,99915 & 0,99929 & 1.477 & 1.349 & 1.571 & 1.498 & 1.382 & 1.318 & 1.226 & 1.170 \\
\hline 05-09 & 0,99980 & 0,99986 & 1.501 & 1.438 & 1.476 & 1.348 & 1.570 & 1.497 & 1.381 & 1.317 \\
\hline $10-14$ & 0,99914 & 0,99965 & 1.492 & 1.425 & 1.501 & 1.438 & 1.475 & 1.348 & 1.569 & 1.497 \\
\hline $15-19$ & 0,99742 & 0,99915 & 1.652 & 1.480 & 1.491 & 1.425 & 1.499 & 1.437 & 1.474 & 1.347 \\
\hline $20-24$ & 0,99597 & 0,99869 & 1.679 & 1.683 & 1.648 & 1.479 & 1.487 & 1.423 & 1.496 & 1.436 \\
\hline $25-29$ & 0,99586 & 0,99841 & 1.862 & 1.913 & 1.672 & 1.681 & 1.641 & 1.477 & 1.481 & 1.421 \\
\hline $30-34$ & 0,99585 & 0,99805 & 2.346 & 2.350 & 1.854 & 1.910 & 1.665 & 1.678 & 1.634 & 1.474 \\
\hline $35-39$ & 0,99431 & 0,99715 & 2.419 & 2.437 & 2.336 & 2.345 & 1.847 & 1.906 & 1.658 & 1.675 \\
\hline $40-44$ & 0,99111 & 0,99558 & 2.256 & 2.408 & 2.405 & 2.430 & 2.323 & 2.339 & 1.836 & 1.901 \\
\hline $45-49$ & 0,98420 & 0,99261 & 2.197 & 2.447 & 2.236 & 2.397 & 2.384 & 2.419 & 2.302 & 2.328 \\
\hline $50-54$ & 0,97641 & 0,98937 & 2.156 & 2.362 & 2.162 & 2.429 & 2.201 & 2.380 & 2.346 & 2.401 \\
\hline $55-59$ & 0,96641 & 0,98519 & 1.756 & 1.798 & 2.105 & 2.337 & 2.111 & 2.403 & 2.149 & 2.354 \\
\hline $60-64$ & 0,94913 & 0,97805 & 1.455 & 1.590 & 1.697 & 1.771 & 2.034 & 2.302 & 2.040 & 2.367 \\
\hline $65-69$ & 0,91944 & 0,96333 & 1.206 & 1.399 & 1.381 & 1.555 & 1.611 & 1.732 & 1.931 & 2.252 \\
\hline $70-74$ & 0,85556 & 0,92576 & 877 & 1.101 & 1.109 & 1.348 & 1.270 & 1.498 & 1.481 & 1.669 \\
\hline $75-79$ & 0,74531 & 0,84547 & 896 & 1.175 & 750 & 1.019 & 949 & 1.248 & 1.086 & 1.387 \\
\hline 80-84 & 0,59702 & 0,71142 & 606 & 1.010 & 668 & 993 & 559 & 862 & 707 & 1.055 \\
\hline 85-89 & 0,43219 & 0,53445 & 380 & 731 & 362 & 719 & 399 & 707 & 334 & 613 \\
\hline $90-94$ & 0,27621 & 0,34815 & 108 & 325 & 164 & 391 & 156 & 384 & 172 & 378 \\
\hline 95-99 & 0,04889 & 0,16341 & 31 & 125 & 30 & 113 & 45 & 136 & 43 & 134 \\
\hline \multirow[t]{3}{*}{$100 y+$} & 0,00000 & 0,00000 & 2 & 15 & 2 & 20 & 1 & 18 & 2 & 22 \\
\hline & Subtotal & & 28.354 & 30.561 & 28.620 & 30.646 & 28.609 & 30.513 & 28.350 & 30.199 \\
\hline & Total & & \multicolumn{2}{|c|}{58.915} & \multicolumn{2}{|c|}{59.266} & \multicolumn{2}{|c|}{59.122} & \multicolumn{2}{|c|}{58.549} \\
\hline
\end{tabular}


Figura 7. Comparación de pirámides de población en 2012 y 2027 (e.1).

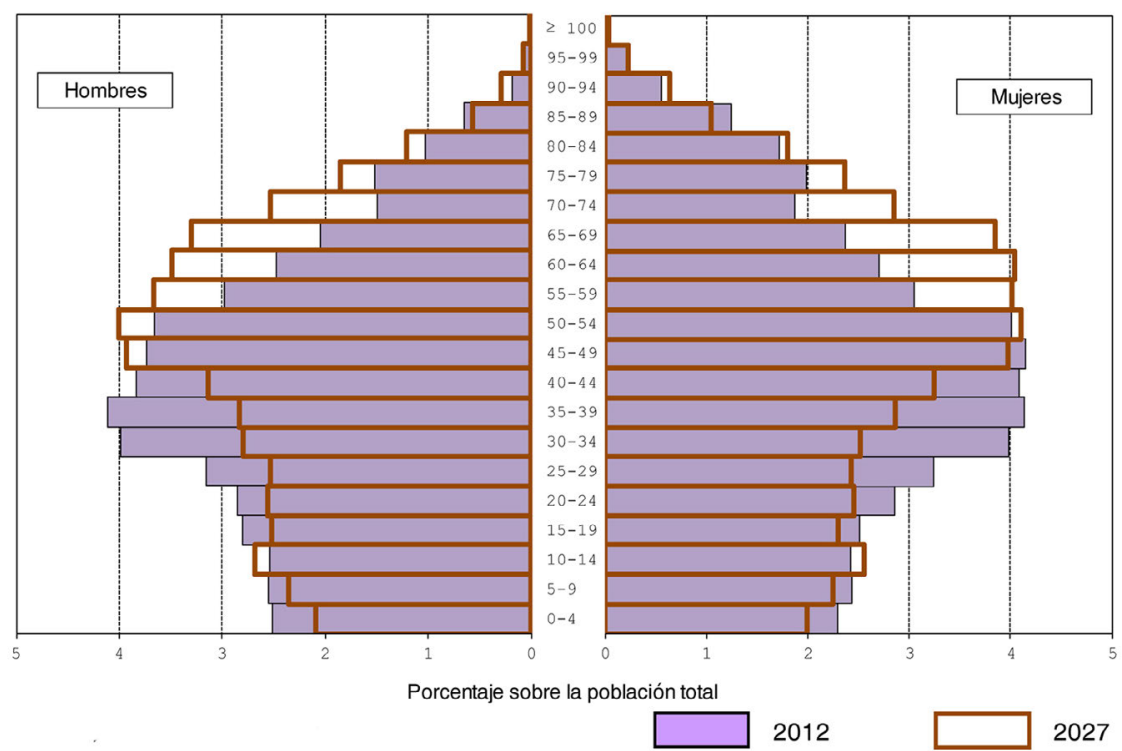

Se trata de un escenario conservador pero optimista, ya que al no tener en cuenta las migraciones sobrevalora la población final.

\subsubsection{Escenario 2 (Tablas 12, 13, 14 y Figura 8):}

- Aumento de la esperanza media de vida al nacer progresiva, con un promedio para el periodo analizado de 81,64 años para los varones y 87,51 para las mujeres. Las perspectivas de paso entre cohortes etarias se incrementan según las previsiones del Instituto Nacional de Estadística. Los efectos más intensos se concentran en los grupos de mayor edad.

- Mantenimiento de las actuales tasas de fecundidad durante el quinquenio 2012-2017, debido a la crisis económica, e incremento de las mismas en un 10\% durante los quinquenios 2017-2022 y 2022-2027. El índice sintético de fecundidad o número medio de hijos por mujer en cada quinquenio ascendería de 1,50 a 1,64 y 1,81, respectivamente. Estos índices superan los estimados por el Instituto Nacional de Estadística.

- Ausencia de movimientos migratorios.

Tabla 12. Tabla de mortalidad modelo para Ávila capital, 2007-2012, para una esperanza de vida media al nacer de 81,64 años para los varones y 87,51 para las mujeres

\begin{tabular}{|c|c|c|c|c|c|c|c|c|c|c|}
\hline \multirow{2}{*}{ Edad } & \multicolumn{2}{|c|}{$l_{x}$} & \multicolumn{2}{|c|}{${ }_{5} q_{x}$} & \multicolumn{2}{|c|}{${ }_{5} L_{x}$} & \multicolumn{2}{|c|}{${ }_{5} T_{x}$} & \multicolumn{2}{|c|}{$e_{x}$} \\
\hline & Varones & Mujeres & Varones & Mujeres & Varones & Mujeres & Varones & Mujeres & Varones & Mujeres \\
\hline 0 & 100.000 & 100.001 & 2,46 & 1,89 & 99.779 & 99.831 & 8.163 .505 & 8.751 .536 & 81,64 & 87,51 \\
\hline 1 & 99.754 & 99.812 & 1,19 & 0,96 & 398.709 & 398.999 & 8.063 .726 & 8.651 .705 & 80,84 & 86,68 \\
\hline 5 & 99.636 & 99.716 & 0,07 & 0,04 & 498.162 & 498.572 & 7.665 .017 & 8.252 .706 & 76,93 & 82,76 \\
\hline 10 & 99.629 & 99.712 & 0,08 & 0,03 & 498.125 & 498.554 & 7.166 .855 & 7.754 .135 & 71,94 & 77,76 \\
\hline 15 & 99.621 & 99.709 & 0,96 & 0,29 & 497.867 & 498.472 & 6.668 .730 & 7.255 .581 & 66,94 & 72,77 \\
\hline 20 & 99.525 & 99.680 & 3,11 & 0,86 & 496.852 & 498.185 & 6.170 .863 & 6.757 .109 & 62,00 & 67,79 \\
\hline 25 & 99.215 & 99.594 & 3,98 & 1,19 & 495.089 & 497.675 & 5.674 .011 & 6.258 .923 & 57,19 & 62,84 \\
\hline 30 & 98.820 & 99.476 & 3,26 & 1,26 & 493.296 & 497.066 & 5.178 .922 & 5.761 .248 & 52,41 & 57,92 \\
\hline 35 & 98.498 & 99.351 & 3,55 & 1,55 & 491.617 & 496.368 & 4.685 .626 & 5.264 .183 & 47,57 & 52,99 \\
\hline 40 & 98.149 & 99.197 & 5,55 & 2,45 & 489.381 & 495.376 & 4.194 .010 & 4.767 .815 & 42,73 & 48,06 \\
\hline 45 & 97.604 & 98.954 & 8,56 & 3,72 & 485.932 & 493.849 & 3.704 .628 & 4.272 .438 & 37,96 & 43,18 \\
\hline 50 & 96.769 & 98.586 & 17,90 & 7,35 & 479.514 & 491.119 & 3.218 .697 & 3.778 .589 & 33,26 & 38,33 \\
\hline 55 & 95.037 & 97.862 & 20,20 & 7,91 & 470.386 & 487.373 & 2.739 .183 & 3.287 .470 & 28,82 & 33,59 \\
\hline 60 & 93.117 & 97.087 & 30,79 & 11,52 & 458.420 & 482.641 & 2.268 .797 & 2.800 .097 & 24,36 & 28,84 \\
\hline 65 & 90.250 & 95.969 & 44,20 & 15,68 & 441.279 & 476.085 & 1.810 .377 & 2.317 .456 & 20,06 & 24,15 \\
\hline 70 & 86.261 & 94.465 & 74,45 & 29,05 & 415.249 & 465.464 & 1.369 .099 & 1.841 .371 & 15,87 & 19,49 \\
\hline 75 & 79.838 & 91.721 & 156,21 & 71,19 & 368.013 & 442.281 & 953.850 & 1.375 .906 & 11,95 & 15,00 \\
\hline 80 & 67.367 & 85.191 & 291,13 & 167,50 & 287.803 & 390.283 & 585.837 & 933.625 & 8,70 & 10,96 \\
\hline 85 & 47.754 & 70.922 & 474,78 & 334,85 & 182.090 & 295.238 & 298.035 & 543.343 & 6,24 & 7,66 \\
\hline 90 & 25.082 & 47.174 & 619,56 & 557,07 & 86.560 & 170.171 & 115.944 & 248.104 & 4,62 & 5,26 \\
\hline 95 & 9.542 & 20.895 & 832,12 & 768,01 & 27.860 & 64.355 & 29.384 & 77.933 & 3,08 & 3,73 \\
\hline 100 & 1.602 & 4.847 & 1000,00 & 1000,00 & 1.525 & 13.578 & 1.525 & 13.578 & 0,95 & 2,80 \\
\hline
\end{tabular}


Tabla 13. Cálculo del número de nacimientos con fecundidad constante durante el primer quinqueno y en aumento $(10 \%)$ en los dos quinquenos siguientes

\begin{tabular}{|c|c|c|c|c|c|c|}
\hline \multirow[b]{2}{*}{ Edad } & \multirow[b]{2}{*}{${ }_{5} f_{x}$} & \multirow[b]{2}{*}{$\sum_{5} f_{x}$} & \multicolumn{3}{|c|}{ Mujeres } & \multirow[b]{2}{*}{ Nacimientos } \\
\hline & & & 2012 & 2017 & Promedio & \\
\hline $15-19$ & 11,96 & 59,80 & 1.480 & 1.425 & 1.452 & 17 \\
\hline $20-24$ & 28,99 & 204,76 & 1.683 & 1.479 & 1.581 & 46 \\
\hline $25-29$ & 60,68 & 508,17 & 1.913 & 1.681 & 1.797 & 109 \\
\hline $30-34$ & 109,30 & $1.054,68$ & 2.350 & 1.911 & 2.130 & 233 \\
\hline $35-39$ & 74,38 & $1.426,56$ & 2.437 & 2.347 & 2.392 & 178 \\
\hline $40-44$ & 12,32 & $1.488,14$ & 2.408 & 2.432 & 2.420 & 30 \\
\hline $45-49$ & 1,41 & $1.495,18$ & 2.447 & 2.401 & 2.424 & 3 \\
\hline \multicolumn{2}{|c|}{ ISF 2012-2016 } & 1,50 & \multicolumn{3}{|c|}{ Nacimientos anuales } & 616 \\
\hline \multicolumn{2}{|c|}{ Nacimientos 2012-2016 } & 3.081 & Varones & 1.578 & Mujeres & 1.504 \\
\hline \multicolumn{6}{|c|}{ Variación estimada de la fecundidad } & $0 \%$ \\
\hline
\end{tabular}

\begin{tabular}{|c|c|c|c|c|c|c|}
\hline \multirow{2}{*}{ Edad } & \multirow{2}{*}{${ }_{5} f_{x}$} & \multirow{2}{*}{$\sum_{5} f_{x}$} & \multicolumn{3}{|c|}{ Mujeres } & \multirow{2}{*}{ Nacimientos } \\
\hline & & & 2017 & 2022 & Promedio & \\
\hline $15-19$ & 13,16 & 65,78 & 1.425 & 1.438 & 1.431 & 19 \\
\hline $20-24$ & 31,89 & 225,24 & 1.479 & 1.424 & 1.452 & 46 \\
\hline $25-29$ & 66,75 & 558,99 & 1.681 & 1.478 & 1.579 & 105 \\
\hline $30-34$ & 120,23 & $1.160,14$ & 1.911 & 1.679 & 1.795 & 216 \\
\hline $35-39$ & 81,81 & $1.569,21$ & 2.347 & 1.908 & 2.127 & 174 \\
\hline $40-44$ & 13,55 & $1.636,96$ & 2.432 & 2.342 & 2.387 & 32 \\
\hline $45-49$ & 1,55 & $1.644,70$ & 2.401 & 2.425 & 2.413 & 4 \\
\hline \multicolumn{2}{|c|}{ ISF 2017-2021 } & 1,64 & \multicolumn{3}{|c|}{ Nacimientos anuales } & 596 \\
\hline \multicolumn{2}{|c|}{ Nacimientos 2017-2021 } & 2.982 & Varones & 1.527 & Mujeres & 1.455 \\
\hline \multicolumn{6}{|c|}{ Variación estimada de la fecundidad } & $10 \%$ \\
\hline
\end{tabular}

\begin{tabular}{|c|c|c|c|c|c|c|}
\hline \multirow[b]{2}{*}{ Edad } & \multirow[b]{2}{*}{${ }_{5} f_{x}$} & \multirow[b]{2}{*}{$\sum_{5} f_{x}$} & \multicolumn{3}{|c|}{ Mujeres } & \multirow[b]{2}{*}{ Nacimientos } \\
\hline & & & 2022 & 2027 & Promedio & \\
\hline $15-19$ & 14,47 & 72,35 & 1.438 & 1.348 & 1.393 & 20 \\
\hline $20-24$ & 35,08 & 247,76 & 1.424 & 1.437 & 1.430 & 50 \\
\hline $25-29$ & 73,43 & 614,89 & 1.478 & 1.422 & 1.450 & 106 \\
\hline $30-34$ & 132,25 & $1.276,16$ & 1.679 & 1.476 & 1.578 & 209 \\
\hline $35-39$ & 90,00 & $1.726,14$ & 1.908 & 1.677 & 1.792 & 161 \\
\hline $40-44$ & 14,90 & $1.800,65$ & 2.342 & 1.904 & 2.123 & 32 \\
\hline $45-49$ & 1,70 & $1.809,17$ & 2.425 & 2.335 & 2.380 & 4 \\
\hline \multicolumn{2}{|c|}{ ISF 2022-2026 } & 1,81 & \multicolumn{3}{|c|}{ Nacimientos anuales } & 582 \\
\hline \multicolumn{2}{|c|}{ Nacimientos 2022-2026 } & 2.912 & Varones & 1.491 & Mujeres & 1.421 \\
\hline
\end{tabular}

Tabla 14. Evolución de la pirámide de población de Ávila capital en ausencia de migraciones

\begin{tabular}{|c|c|c|c|c|c|c|c|c|c|c|}
\hline \multirow{2}{*}{ Edad } & \multicolumn{2}{|c|}{${ }_{5} S_{x}$} & \multicolumn{2}{|c|}{2012} & \multicolumn{2}{|c|}{2017} & \multicolumn{2}{|c|}{2022} & \multicolumn{2}{|c|}{2027} \\
\hline & Varones & Mujeres & Varones & Mujeres & Varones & Mujeres & Varones & Mujeres & Varones & Mujeres \\
\hline Ntos-0 & 0,99698 & 0,99766 & & & & & & & & \\
\hline $0-4$ & 0,99934 & 0,99948 & 1.477 & 1.349 & 1.573 & 1.500 & 1.522 & 1.452 & 1.487 & 1.418 \\
\hline 05-09 & 0,99993 & 0,99996 & 1.501 & 1.438 & 1.476 & 1.348 & 1.572 & 1.499 & 1.521 & 1.451 \\
\hline $10-14$ & 0,99948 & 0,99984 & 1.492 & 1.425 & 1.501 & 1.438 & 1.476 & 1.348 & 1.572 & 1.499 \\
\hline $15-19$ & 0,99796 & 0,99942 & 1.652 & 1.480 & 1.491 & 1.425 & 1.500 & 1.438 & 1.475 & 1.348 \\
\hline $20-24$ & 0,99645 & 0,99898 & 1.679 & 1.683 & 1.649 & 1.479 & 1.488 & 1.424 & 1.497 & 1.437 \\
\hline $25-29$ & 0,99638 & 0,99878 & 1.862 & 1.913 & 1.673 & 1.681 & 1.643 & 1.478 & 1.483 & 1.422 \\
\hline $30-34$ & 0,99660 & 0,99860 & 2.346 & 2.350 & 1.855 & 1.911 & 1.667 & 1.679 & 1.637 & 1.476 \\
\hline $35-39$ & 0,99545 & 0,99800 & 2.419 & 2.437 & 2.338 & 2.347 & 1.849 & 1.908 & 1.661 & 1.677 \\
\hline $40-44$ & 0,99295 & 0,99692 & 2.256 & 2.408 & 2.408 & 2.432 & 2.327 & 2.342 & 1.841 & 1.904 \\
\hline $45-49$ & 0,98679 & 0,99447 & 2.197 & 2.447 & 2.240 & 2.401 & 2.391 & 2.425 & 2.311 & 2.335 \\
\hline $50-54$ & 0,98096 & 0,99237 & 2.156 & 2.362 & 2.168 & 2.433 & 2.211 & 2.387 & 2.359 & 2.411 \\
\hline $55-59$ & 0,97456 & 0,99029 & 1.756 & 1.798 & 2.115 & 2.344 & 2.127 & 2.415 & 2.168 & 2.369 \\
\hline $60-64$ & 0,96261 & 0,98642 & 1.455 & 1.590 & 1.711 & 1.781 & 2.061 & 2.321 & 2.073 & 2.391 \\
\hline $65-69$ & 0,94101 & 0,97769 & 1.206 & 1.399 & 1.401 & 1.568 & 1.647 & 1.756 & 1.984 & 2.290 \\
\hline $70-74$ & 0,88625 & 0,95019 & 877 & 1.101 & 1.135 & 1.368 & 1.318 & 1.533 & 1.550 & 1.717 \\
\hline $75-79$ & 0,78204 & 0,88243 & 896 & 1.175 & 777 & 1.046 & 1.006 & 1.300 & 1.168 & 1.457 \\
\hline $80-84$ & 0,63269 & 0,75647 & 606 & 1.010 & 701 & 1.037 & 608 & 923 & 787 & 1.147 \\
\hline $85-89$ & 0,47537 & 0,57638 & 380 & 731 & 383 & 764 & 443 & 784 & 385 & 698 \\
\hline $90-94$ & 0,32186 & 0,37818 & 108 & 325 & 181 & 421 & 182 & 440 & 211 & 452 \\
\hline $95-99$ & 0,05189 & 0,17423 & 31 & 125 & 35 & 123 & 58 & 159 & 59 & 167 \\
\hline \multirow[t]{3}{*}{$100 y+$} & 0,00000 & 0,00000 & 2 & 15 & 2 & 22 & 2 & 21 & 3 & 28 \\
\hline & Subtotal & & 28.354 & 30.561 & 28.812 & 30.869 & 29.098 & 31.034 & 29.231 & 31.095 \\
\hline & Total & & \multicolumn{2}{|c|}{58.915} & \multicolumn{2}{|c|}{59.681} & \multicolumn{2}{|c|}{60.133} & \multicolumn{2}{|c|}{60.325} \\
\hline
\end{tabular}


Figura 8. Comparación de pirámides de población en 2012 y 2027 (e.2).

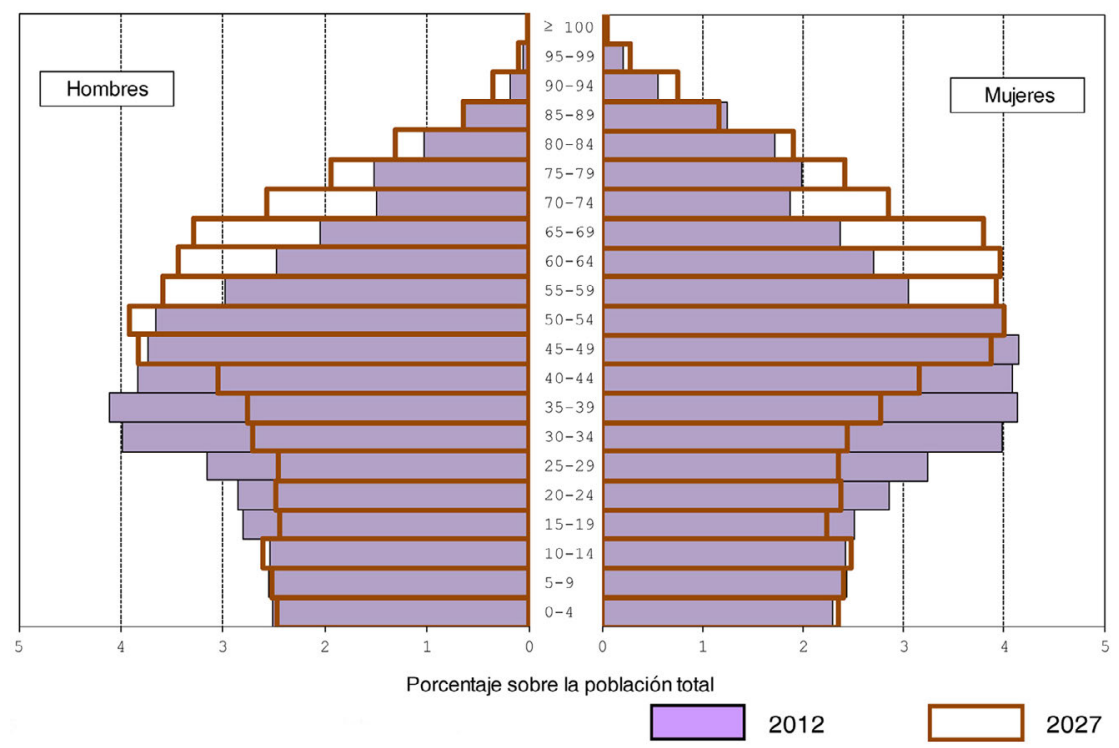

Se trata de un escenario muy optimista, pues no solo excluye migraciones, negativas en estos momentos tanto en sus saldos internos como externos, sino que aúna incrementos posibles de la esperanza de vida con otros demasiados elevados de la fecundidad ${ }^{6}$.

\subsubsection{Escenario 3 (Tabla 15, 16 y Figura 9):}

- Idénticos cambios en la esperanza de vida y fecundidad que en el Escenario 2 (Tabla 12).

- Migraciones internas según las estimaciones del Instituto Nacional de Estadística.

- Migraciones externas nulas entre 2012-2017 y positivas en 2017-2022 y 2022-2027, de acuerdo a las estimaciones del Instituto Nacional de Estadística.

Tabla 15. Cálculo del número de nacimientos con fecundidad constante durante el primer quinqueno y en aumento (10\%) en los dos quinquenos siguientes

\begin{tabular}{|c|c|c|c|c|c|c|}
\hline \multirow{2}{*}{ Edad } & \multirow{2}{*}{${ }_{5} f_{x}$} & \multirow{2}{*}{$\sum_{5} f_{x}$} & \multicolumn{3}{|c|}{ Mujeres } & \multirow{2}{*}{ Nacimientos } \\
\hline & & & 2012 & 2017 & Promedio & \\
\hline $15-19$ & 11,96 & 59,80 & 1.480 & 1.335 & 1.408 & 17 \\
\hline $20-24$ & 28,99 & 204,76 & 1.683 & 1.332 & 1.507 & 44 \\
\hline $25-29$ & 60,68 & 508,17 & 1.913 & 1.492 & 1.703 & 103 \\
\hline $30-34$ & 109,30 & $1.054,68$ & 2.350 & 1.714 & 2.032 & 222 \\
\hline $35-39$ & 74,38 & $1.426,56$ & 2.437 & 2.193 & 2.315 & 172 \\
\hline $40-44$ & 12,32 & $1.488,14$ & 2.408 & 2.341 & 2.374 & 29 \\
\hline $45-49$ & 1,41 & $1.495,18$ & 2.447 & 2.315 & 2.381 & 3 \\
\hline \multicolumn{2}{|c|}{ ISF $2012-2016$} & 1,50 & \multicolumn{3}{|c|}{ Nacimientos anuales } & 591 \\
\hline \multirow{2}{*}{\multicolumn{2}{|c|}{ Nacimientos 2012-2016 }} & 2.954 & Varones & 1.512 & Mujeres & 1.441 \\
\hline & & & \multicolumn{3}{|c|}{ Variación estimada de la fecundidad } & $0 \%$ \\
\hline
\end{tabular}

\begin{tabular}{|c|c|c|c|c|c|c|}
\hline \multirow{2}{*}{ Edad } & \multirow{2}{*}{${ }_{5} f_{x}$} & \multirow{2}{*}{$\sum_{5} f_{x}$} & \multicolumn{3}{|c|}{ Mujeres } & \multirow{2}{*}{ Nacimientos } \\
\hline & & & 2017 & 2022 & Promedio & \\
\hline $15-19$ & 13,16 & 65,78 & 1.335 & 1.319 & 1.327 & 17 \\
\hline $20-24$ & 31,89 & 225,24 & 1.332 & 1.259 & 1.295 & 41 \\
\hline $25-29$ & 66,75 & 558,99 & 1.492 & 1.248 & 1.370 & 91 \\
\hline $30-34$ & 120,23 & $1.160,14$ & 1.714 & 1.412 & 1.563 & 188 \\
\hline $35-39$ & 81,81 & $1.569,21$ & 2.193 & 1.639 & 1.916 & 157 \\
\hline $40-44$ & 13,55 & $1.636,96$ & 2.341 & 2.137 & 2.239 & 30 \\
\hline $45-49$ & 1,55 & $1.644,70$ & 2.315 & 2.276 & 2.295 & 4 \\
\hline \multicolumn{2}{|c|}{ ISF } & 1,64 & \multicolumn{3}{|c|}{ Nacimientos anuales } & 529 \\
\hline \multirow{2}{*}{\multicolumn{2}{|c|}{ Nacimientos 2017-2021 }} & 2.644 & Varones & 1.354 & Mujeres & 1.290 \\
\hline & & & & \multicolumn{2}{|c|}{ Variación estimada de la fecundida } & $10 \%$ \\
\hline
\end{tabular}

6 Teniendo en cuenta que el índice sintético de fecundidad ha descendido a 1,4 en 2012-2013 y en la proyección se ha utilizado el del quinquenio 2007-2012 (1,5), la presencia de unos saldos migratorios negativos implicaría una mayor caída de la fecundidad al ser los jóvenes los que emigran. 


\begin{tabular}{|c|c|c|c|c|c|c|}
\hline \multirow{2}{*}{ Edad } & \multirow[b]{2}{*}{${ }_{5} f_{x}$} & \multirow{2}{*}{$\sum_{5} f_{x}$} & \multicolumn{3}{|c|}{ Mujeres } & \multirow{2}{*}{ Nacimientos } \\
\hline & & & 2022 & 2027 & Promedio & \\
\hline $15-19$ & 14,47 & 72,35 & 1.319 & 1.182 & 1.250 & 18 \\
\hline $20-24$ & 35,08 & 247,76 & 1.259 & 1.245 & 1.252 & 44 \\
\hline $25-29$ & 73,43 & 614,89 & 1.248 & 1.184 & 1.216 & 89 \\
\hline $30-34$ & 132,25 & $1.276,16$ & 1.412 & 1.181 & 1.296 & 171 \\
\hline $35-39$ & 90,00 & $1.726,14$ & 1.639 & 1.353 & 1.496 & 135 \\
\hline $40-44$ & 14,90 & $1.800,65$ & 2.137 & 1.592 & 1.864 & 28 \\
\hline $45-49$ & 1,70 & $1.809,17$ & 2.276 & 2.073 & 2.175 & 4 \\
\hline \multicolumn{2}{|c|}{ ISF } & 1,81 & \multicolumn{3}{|c|}{ Nacimientos anuales } & 489 \\
\hline \multicolumn{2}{|c|}{ Nacimientos 2022-2026 } & 2.444 & Varones & 1.251 & Mujeres & 1.193 \\
\hline \multicolumn{6}{|c|}{ Variación estimada de la fecundidad } & $10 \%$ \\
\hline
\end{tabular}

Tabla 16. Evolución de la pirámide de población de Ávila capital en presencia de migraciones

\begin{tabular}{|c|c|c|c|c|c|c|c|c|c|c|}
\hline \multirow{2}{*}{ Edad } & \multicolumn{2}{|c|}{${ }_{5} S_{x}$} & \multicolumn{2}{|c|}{2012} & \multicolumn{2}{|c|}{2017} & \multicolumn{2}{|c|}{2022} & \multicolumn{2}{|c|}{2027} \\
\hline & Varones & Mujeres & Varones & Mujeres & Varones & Mujeres & Varones & Mujeres & Varones & Mujeres \\
\hline Ntos-0 & 0,99698 & 0,99766 & & & & & & & & \\
\hline $0-4$ & 0,99934 & 0,99948 & 1.477 & 1.349 & 1.397 & 1.330 & 1.282 & 1.240 & 1.186 & 1.146 \\
\hline 05-09 & 0,99993 & 0,99996 & 1.501 & 1.438 & 1.412 & 1.265 & 1.373 & 1.293 & 1.263 & 1.206 \\
\hline $10-14$ & 0,99948 & 0,99984 & 1.492 & 1.425 & 1.439 & 1.369 & 1.400 & 1.229 & 1.363 & 1.259 \\
\hline $15-19$ & 0,99796 & 0,99942 & 1.652 & 1.480 & 1.413 & 1.335 & 1.421 & 1.319 & 1.381 & 1.182 \\
\hline $20-24$ & 0,99645 & 0,99898 & 1.679 & 1.683 & 1.531 & 1.332 & 1.369 & 1.259 & 1.377 & 1.245 \\
\hline $25-29$ & 0,99638 & 0,99878 & 1.862 & 1.913 & 1.502 & 1.492 & 1.449 & 1.248 & 1.291 & 1.184 \\
\hline $30-34$ & 0,99660 & 0,99860 & 2.346 & 2.350 & 1.643 & 1.714 & 1.401 & 1.412 & 1.356 & 1.181 \\
\hline $35-39$ & 0,99545 & 0,99800 & 2.419 & 2.437 & 2.140 & 2.193 & 1.542 & 1.639 & 1.322 & 1.353 \\
\hline $40-44$ & 0,99295 & 0,99692 & 2.256 & 2.408 & 2.267 & 2.341 & 2.066 & 2.137 & 1.481 & 1.592 \\
\hline $45-49$ & 0,98679 & 0,99447 & 2.197 & 2.447 & 2.154 & 2.315 & 2.218 & 2.276 & 2.014 & 2.073 \\
\hline $50-54$ & 0,98096 & 0,99237 & 2.156 & 2.362 & 2.117 & 2.359 & 2.114 & 2.257 & 2.163 & 2.215 \\
\hline $55-59$ & 0,97456 & 0,99029 & 1.756 & 1.798 & 2.097 & 2.289 & 2.086 & 2.305 & 2.070 & 2.200 \\
\hline $60-64$ & 0,96261 & 0,98642 & 1.455 & 1.590 & 1.678 & 1.769 & 2.027 & 2.269 & 2.000 & 2.280 \\
\hline $65-69$ & 0,94101 & 0,97769 & 1.206 & 1.399 & 1.367 & 1.572 & 1.604 & 1.763 & 1.913 & 2.252 \\
\hline $70-74$ & 0,88625 & 0,95019 & 877 & 1.101 & 1.113 & 1.344 & 1.294 & 1.529 & 1.483 & 1.699 \\
\hline $75-79$ & 0,78204 & 0,88243 & 896 & 1.175 & 762 & 1.023 & 1.032 & 1.293 & 1.129 & 1.428 \\
\hline $80-84$ & 0,63269 & 0,75647 & 606 & 1.010 & 687 & 1.016 & 661 & 954 & 792 & 1.122 \\
\hline $85-89$ & 0,47537 & 0,57638 & 380 & 731 & 371 & 754 & 523 & 887 & 403 & 712 \\
\hline $90-94$ & 0,32186 & 0,37818 & 108 & 325 & 176 & 417 & 228 & 566 & 240 & 506 \\
\hline 95-99 & 0,05189 & 0,17423 & 31 & 125 & 34 & 122 & 81 & 239 & 71 & 212 \\
\hline \multirow[t]{3}{*}{$100 y+$} & 0,00000 & 0,00000 & 2 & 15 & 2 & 22 & 11 & 46 & 4 & 41 \\
\hline & Subtotal & & 28.354 & 30.561 & 27.300 & 29.372 & 27.181 & 29.158 & 26.303 & 28.087 \\
\hline & Total & & \multicolumn{2}{|c|}{58.915} & \multicolumn{2}{|c|}{56.672} & \multicolumn{2}{|c|}{56.339} & \multicolumn{2}{|c|}{54.390} \\
\hline
\end{tabular}

Figura 9. Comparación de pirámides de población en 2012 y 2027 (e.3).

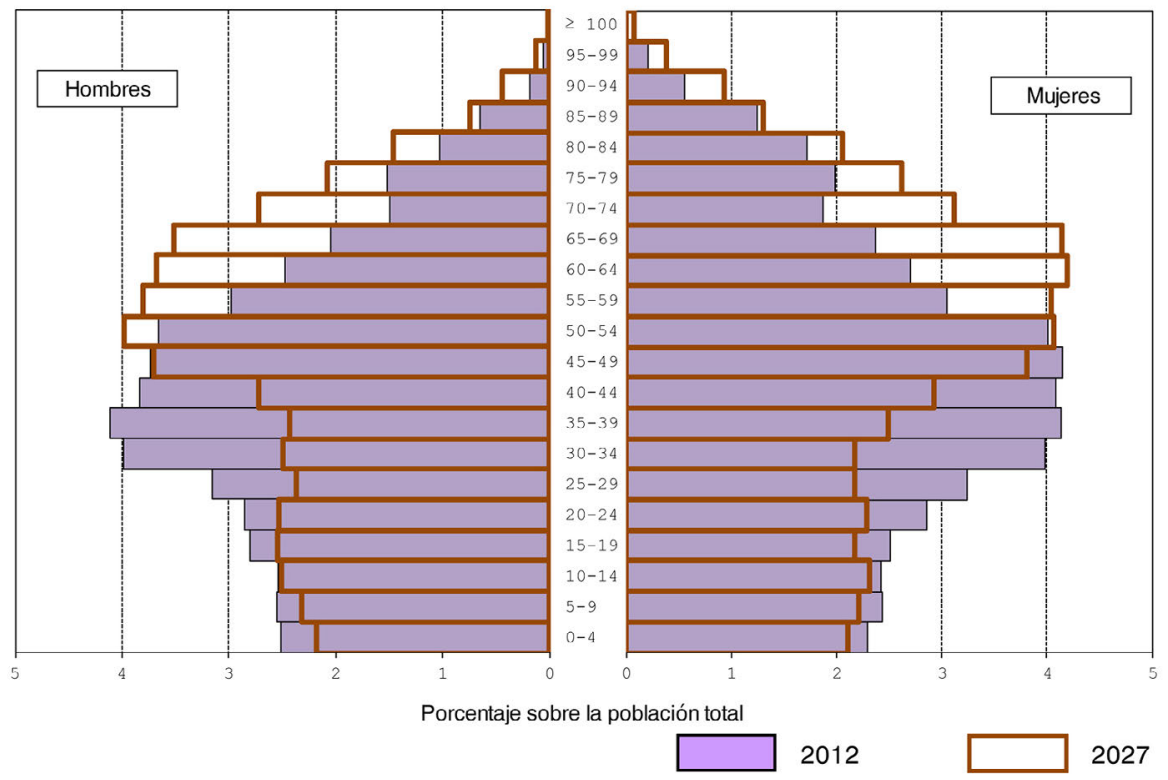

Es un escenario factible en ausencia de grandes cambios en el mercado laboral de la ciudad. Los saldos migratorios externos son favorables pero muy inferiores a los alcanzados en la primera década 
del Siglo XXI, mientras los internos son muy desfavorables. No se ha considerado la emigración exterior durante el quinquenio 2012-2017, que supondría un mayor descenso de la población.

\section{CONCLUSIONES}

La ciudad de Ávila se ha construido pausadamente sobre los mimbres del pasado hasta conformar, en la actualidad, un compacto entramado urbano. Este ha conocido un crecimiento espacial sin precedentes a lo largo de los últimos sesenta años y, particularmente, durante la primera década de los años dos mil, fruto de una vinculación, que no siempre está correspondida, entre la evolución poblacional y el desarrollo residencial.

La positiva evolución demográfica experimentada por Ávila entre 2001 y 2011 (11.041 residentes) solamente puede ser explicada, en el marco de la dinámica expansiva asociada a todas las áreas urbanas de Castilla y León, por un aumento del vecindario en la ciudad compacta, no contando con los procesos de periurbanización consustanciales a la práctica totalidad de las ciudades medias de la Comunidad, como lo atestigua el hecho de que los bordes urbanos de la ciudad se descubren nítidamente por oposición a la dominancia que adquiere la ruralidad en el resto de un término municipal escasamente urbanizado.

Así, con ausencias de crecimientos exógenos de entidad, la ciudad de Ávila se ha desarrollado enormemente en un proceso de ampliación del espacio construido cuyo soporte estratégico se ha fundamentado, además, en la dialéctica establecida entre el centro y la periferia. De este modo, frente al descenso generalizado de la población residente en la ciudad tradicional y los barrios aledaños a esta, dos han sido los grandes segmentos de creación ex nova que concentran los nuevos desarrollos urbanísticos desde el decenio de 1980; los ubicados y expandidos hacia levante a Norte y Sur del espacio nuclear.

1.964 edificios levantados en las dos décadas finales del siglo XX y otros 2.284 a lo largo del lapso 2001-2011 marcan los ritmos de un ensanchamiento del perímetro urbanizado desconocido, en lo que vienen siendo las trazas de la Ávila contemporánea: la finisecular y la del "boom inmobiliario".

Una ciudad que se construye, aparte de por las notables pulsaciones poblacionales, en visos de atonía presente (apenas 250 habitantes más en el balance 2011-2013, por la pérdida de significado de la inmigración extranjera y la atenuación de los saldos positivos de la dinámica natural), dimensionada desorbitadamente por la conjunción de una serie de intereses urbanísticos completamente truncados por el estallido de la crisis que asola el panorama nacional (46\% de la producción inmobiliaria de estos años se encuentra desocupada).

La Ávila de los "100.000", que propugnaba el Plan Estratégico de Desarrollo Industrial de 2006, idea recogida por el Avance del Plan General de Ordenación Urbana en tramitación, parece ser más una utopía que una realidad, a tenor de las proyecciones demográficas realizadas que atisban un horizonte demográfico para el entorno de 2030 de sostenimiento en el mejor de los casos. Es lo que algunos autores han catalogado como "anticipar el futuro al margen de la historia o diseñar una ciudad al margen de la ciudad conocida" (Calderón, 2013: 87). Porque lo cierto es que la dinámica urbana y poblacional abulense no pasa por su momento más halagüeño. Un serio condicionante para esa reestructuración urbana tan necesaria y de la que adolece Ávila a día de hoy.

\section{FUENTES}

Ayuntamiento de Ávila (2010): Revisión del Plan General de Ordenación Urbana de Ávila. Documento de Avance. Información, Análisis y Diagnóstico. Conurma Ingenieros Consultores y Ayuntamiento de Ávila. Ávila, $417 \mathrm{pp}$.

Ayuntamiento de Ávila: Explotación estadística del Padrón Municipal (varios años).

Deloitte (2006): Plan Estratégico de Desarrollo Industrial de la Ciudad de Avila. Ayuntamiento de Ávila y Cámara Oficial de Comercio e Industria de Ávila. Ávila, 3 vols.

Instituto Geográfico Nacional (I.G.N.) y Centro Nacional de Información Geográfica (C.N.I.G.): Carto-

Ciudad (sistema de información de la red viaria, cartografía urbana y divisiones censal y postal de España).

Instituto Nacional de Estadística (I.N.E.): Censo de Población y Viviendas (varios años).

Instituto Nacional de Estadística (I.N.E.): Estadística de Variaciones Residenciales (varios años).

Instituto Nacional de Estadística (I.N.E.): Movimiento Natural de la Población (varios años).

Instituto Nacional de Estadística (I.N.E.): Padrón Municipal de Habitantes (varios años).

Ministerio de Fomento: Transacciones inmobiliarias (compraventa).

SIE (Almacén de datos multidimensional de la Junta de Castilla y León). 


\section{BIBLIOGRAFÍA}

CALDERÓN CALDERÓN, B. (2001): "Un espacio creado y transformado por el permanente conflicto entre centro y periferia: una hipótesis -más- para interpretar el modelo de crecimiento urbano en España". En MANERO, F. (coord.): Espacio Natural y Dinámicas Territoriales. Homenaje al Dr. D. Jesús García Fernández. Ed. Universidad de Valladolid. Valladolid, pp. 589-598.

CALDERÓN CALDERÓN, B. (2012): "Áreas urbanas y estructura de las ciudades de Castilla y León". En DELGADO URRECHO, J.M ${ }^{a}$. (dir.): Población y poblamiento en Castilla y León. Ed. Consejo Económico y Social de Castilla y León. Valladolid, pp. 739-810.

CALDERÓN CALDERÓN, B. (2013): "De la ley al territorio: legislación, planeamiento y ciudad en los planes generales de Castilla y León 1997-2010”. En VALENZUELA RUBIO, M. (coord.): Las ciudades españolas en la encrucijada: entre el 'boom' inmobiliario y la crisis económica. Ed. Real Sociedad Geográfica. Madrid, pp. 77-110.

MARTÍNEZ FERNÁNDEZ, L.C. y LUENGO GALLEGO, J.A. (2005): "Población y estructura urbana: aproximación a la diferenciación demográfica de la ciudad de Segovia", en Investigaciones Geográficas, $\mathrm{n}^{\mathrm{o}} 37$, pp. 47-58.

RIVAS SANZ, J.L. (2007): "El proyecto de adaptación del Plan General de Ávila a la Ley de Urbanismo de Castilla y León y a su Reglamento, 1998-2005", en Urban, n 12, pp. 66-83.

SERRANO MARTÍNEZ, J.Ma . (2004): "Expansión del parque inmobiliario en España. Algunas reflexiones desde la perspectiva territorial", en Boletín Económico de ICE, no 2798, pp. 11-30.

SERRANO MARTÍNEZ, J.Ma . (2010): "La edificación de viviendas en España, final del ciclo y iocaso del modelo?", en Boletín Económico de ICE, n 2981, pp. 37-55.

VILLAR CASTRO, J. (1982): Geografía urbana de Ávila: raíces históricas en una ciudad actual. Tesis Doctoral (inédita). Universidad de Salamanca. Salamanca, 1.164 pp. + anexos.

VILLAR CASTRO, J. (1984): "Organización espacial y paisaje arquitectónico en la ciudad medieval. Una aportación geográfica a la historia del urbanismo abulense", en Cuadernos abulenses, no 1, pp. 69-89.

VILLAR CASTRO, J. (1989): "Estructura y tipología de las ciudades castellano-leonesas". En CABO, A. y MANERO, F. (dir.): Geografía de Castilla y León, T. 6. Ed. Ámbito. Valladolid, pp. 132-177.

VILLAR CASTRO, J. (1999): “Ávila: un centro administrativo lastrado de tradición”. En CAMPESINO, A.J. (coord.): Comercio, Turismo y Cambios Funcionales en las Ciudades Españolas Patrimonio de la Humanidad. Ed. Cámara de Comercio e Industria de Cáceres. Cáceres, pp. 61-80. 